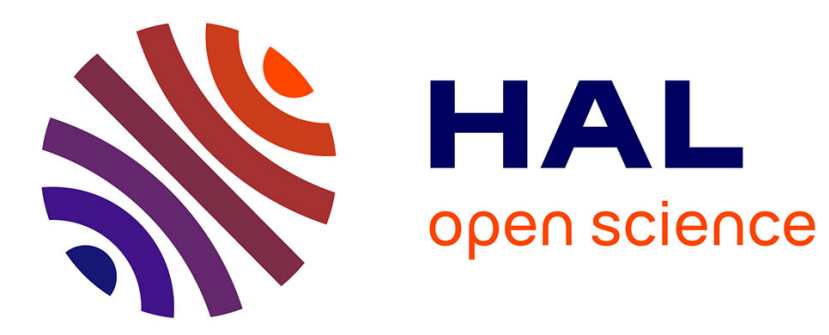

\title{
Habitat vertical et habitus lectural
}

Jean-Marie Privat, Marie-Christine Vinson

\section{To cite this version:}

Jean-Marie Privat, Marie-Christine Vinson. Habitat vertical et habitus lectural. Pratiques: linguistique, littérature, didactique, 1986, 52, pp.83-111. 10.3406/prati.1986.1412 . hal-03180243

\section{HAL Id: hal-03180243 \\ https://hal.univ-lorraine.fr/hal-03180243}

Submitted on 24 Mar 2021

HAL is a multi-disciplinary open access archive for the deposit and dissemination of scientific research documents, whether they are published or not. The documents may come from teaching and research institutions in France or abroad, or from public or private research centers.
L'archive ouverte pluridisciplinaire HAL, est destinée au dépôt et à la diffusion de documents scientifiques de niveau recherche, publiés ou non, émanant des établissements d'enseignement et de recherche français ou étrangers, des laboratoires publics ou privés. 


\section{Habitat vertical et habitus lectural}

Jean-Marie Privat, Marie-Christine Vinson

\section{Citer ce document / Cite this document :}

Privat Jean-Marie, Vinson Marie-Christine. Habitat vertical et habitus lectural. In: Pratiques : linguistique, littérature, didactique, ${ }^{\circ} 52,1986$. Pratiques de lecture. pp. 83-111;

doi : https://doi.org/10.3406/prati.1986.1412

https://www.persee.fr/doc/prati_0338-2389_1986_num_52_1_1412

Fichier pdf généré le 29/03/2019 


\title{
HABITAT VERTICAL ET HABITUS LECTURAL
}

\author{
Jean-Marie PRIVAT et Marie-Christine VINSON
}

\begin{abstract}
"Lisent ceux qui on vu lire leurs parents et ont vécu dans un environnement familial ou social où on lisait" (1).
\end{abstract}

Pour éviter tout malentendu, il convient de préciser dès le début le sens que nous donnons ici au terme "lecture". Pour ce faire, il nous paraît indispensable de tracer un rapide historique socio-scolaire des pratiques de lecture.

II y a un siècle, la scolarisation gratuite et obligatoire avait pour objectif déclaré l'alphabétisation systématique de toutes les catégories sociales. L'école de Jules Ferry atteint globalement et assez rapidement son but (2) même si la pédagogie à la hussarde de ses maîtres fut marquée de violences symboliques à l'encontre des cultures populaires et/ou régionales. La modernisation de la France rurale et industrielle en était l'enjeu économique et culturel.

Cette alphabétisation généralisée et réussie a satisfait, semble-t-il, pendant longtemps aux besoins et à la bonne conscience culturelle du pays. Jusqu'en 1930 la fréquentation des lycées et collèges reste en effet très limitée $(3,6 \%$ des 11-17 ans en 1930) et socialement, extrêmement élitiste. De 1930 à 1960 la proportion d'enfants ouvriers, par exemple, demeurait " très modeste en valeur absolue" (7,5 \% seulement obtiennent un diplôme du second degré ou du supérieur) même si pour certains la réussite scolaire est alors synonyme d'accès aux nouvelles couches moyennes salariées (3). Avec l'ouverture de plus en plus grande du collège depuis bientôt 30 ans (suppression de l'examen d'entrée en sixième, prolongation de la scolarité obligatoire à 16 ans) le seuil des besoins historiques et collectifs en matière de lecture s'est déplacé, vers le haut. Jean Foucambert a décrit ce nouveau stade en terme de "lecturisation" c'est-à-dire de capacités, pour un lecteur donné, de lire et comprendre avec une relative aisance des messages divers dépourvus de difficultés particulières.

(1) M. Gault. L'Avenir du livre /l, Nouvelle lecture, nouveau lecteur, rapport préparé pour la Commission française pour l'Unesco, Paris, Unesco. 1982, série Etudes sur le livre et la lecture, no 9 cite in Problèmes pclitiques et sociaux, le livre et la lecture en France, no 464, la Documentation française, pp. 34 à 37

(2) Les travaux de F. Furet et J. Ozouf, Lire et écrire, l'alphabetisation des rrancals de Calvin à Jules Ferry. Editions de Minuit, 1977, 2 tomes, permettent d'approcher "I'histoire sociale du rapport differentiel à l'alphabétisation et aux diverses formes de son apprentissage institutionnel selon les périodes, les structures socio-économiques locales et la position des groupes sociaux dans ces structures". (F. Muel, Note critique, Annales E.S.C. JanvierFévrier 1980, p. 90)

(3) J.-P. Terrail, Familles ouvrières, école, destin social (1880-1980), in Revue française de sociologie. Juillet-Sep tembre 1984, pp. 421-436 
Du décryptage minimum à la production réfléchie de sens se distribuent ainsi les niveaux d'apprentissage et les performances de lecture; dans la perspective d'une telle progression, les "liserons" doivent accéder normalement au rang de lecteurs effficaces. II est clair que les lectures de tous les collégiens $n$ 'atteignent pas, de loin, ce niveau d'exigence et que persiste, bien que différée (4), l'élimination d'une masse d'élèves. Cette crise est d'autant plus vive que précisément en période de "crise" la demande d'éducation tend à croître sensiblement et que les nouveaux impératifs de développements culturels et socio-économiques se traduisent, en terme de cursus scolaire, par la volonté officiellement proclamée de conduire $80 \%$ d'une classe d'âge au niveau du baccalauréat, d'ici l'an 2000.

$C^{\prime}$ est dire que nous ne saurions appréhender la lecture in abstracto, en autonomisant les lecteurs de leurs conditions historiques de production et de reproduction. C'est pourquoi alphabétiser la masse des français, pensé autrefois en terme de révolution culturelle - l'apprentissage de la lecture chez les enfants des classes populaires fut "une véritable acculturation, un arrachement à des générations d'analphabétisme" (5) - apparaît désormais comme un minimum culturel. Ainsi les faits établis dans le récent rapport sur l'illettrisme en France (6) ont-ils été perçus comme un intolérable scandale socio-scolaire...

C'est une autre mutation, d'un autre type, qui s'impose. Le procès d'alphabétisation, impératif culturel catégorique, exerce aujourd'hui sur l'apprenant moins une contrainte culturelle (largement intériorisée à travers l'héritage culturel collectif) qu'une contrainte technique liée aux apprentissages spécifiques. La plupart des jeunes élèves sont dans cette situation et plus ou moins rapidement, sauf cas dramatiquement marginaux, sont effectivement alphabétisés.

La lecturisation, pour être accomplie, suppose des comportements de lecteurs beaucoup plus complexes dans lesquels notamment les sujets-lecteurs doivent engager plus de leur personnalité socio-culturelle. La maîtrise simplement scolaire de la lecture, si elle n'est pas "portée" par un minimum de bonne volonté culturelle (lectures personnelles, échanges lecturaux...) ne suffit pas, même en premier cycle, pour dégager des profits scolaires et symboliques. Elle permet tout au plus d'arriver cahin-caha en $3^{\text {ème }}$. En effet, pour nous, les bénéfices de la lecturisation ne sont réellement capitalisés que s'ils s'investissent dans un champ culturel qui lui donne sens et valeurs. Nombre d'élèves qui ne vont pas au lycée ou qui s'y essoufflent doivent une bonne partie de leur orientation et/ou de leurs difficultés au fait que ni eux-mêmes ni leur famille ne participent activement à cette pratique légitime des livres légitimes et ne témoignent d'un intérêt désintéressé pour la lecture qui assurent pourtant avec les apparences de la plus heureuse facilité, les meilleurs réussites scolaires (7). Beaucoup vivent dans un contexte fami-

(4) F. Oeuvrard, "Démocratisation" ou elimination differée? in Actes de la Recherche en sciences sociales, Novembre 1979, pp. $87-97$

(5) J. Hebrard. Les nouveaux lecteurs, in Histoire de l'Edition française, Promodis 1985, tome III, p. 474

(6) V. Espérandieu. A. Lion, J.-P. Bénichou. Des illettrés en France, La Documentation française, Janvier 1984. Les statistiques sur les pratiques d'ecriture sont rares et peu éclairantes; c'est dire que jusqu'à présent du moins, ce type d'activités n'a pas été considéré comme un enjeu culturel et social véritable. Du point de vue pédagogique c'est, de toute manière, sous-évaluer les liens entre lecture et écriture.

(7) J.-C. Passeron observe avec beaucoup d'acuité et d'humour sociologiques que la dévaluation des diplômes qui a rendu pratiquement possible la possession généralisée de cette culture désintéressée tant vantée lorsque des bénefices sociaux y étaient effectivement attachés pour quelques uns est vecues très négativement chez la plupart. L'inflation des dip/omes. Revue française de sociologie, XXIII, 1982, p. 582. Sur "I'écoute sans lendemain ni memoire" et sur "le bruit de fond" qui, en rendant possible une attention oblique, immunise relativement les sujets des classes populaires aux tentatives les plus appuyées d'inculcation, voir la préface de J.Cl Passeron au livre de F. Chevaldonné, La Communication inégale, Ed. du C.N.R.S., 1981. 
lial où l'on ne supporterait pas, comme on dit, de les voir "à longueur de journées dans les livres" et échouent dans des études qui sont comme "une souffrance obligée pour obtenir une bonne situation" (8).

Seule l'idéologie lettrée de la lecture peut se permettre d'oublier dans le tête à texte le complexe socio-culturel qui donne du prix aux pratiques lecturales. De fait,

"Le choix d'un titre, la rencontre d'un texte, son achat ou son emprunt supposent déjà tout un réseau social complexe d'individus que la lecture, à des titres divers, rassemble dans des dispositifs plus ou moins élaborés ou institutionnalisés qui sont le théatre de gestes, d'habitudes, de façons de dire ou de faire ". De même, le livre lu "on en parle, on le recommande, on le prête, on le raconte ou le commente... D'autres rencontres s'organisent alors, spontanées ou réglées qui prolongent le rapport premier du texte au lecteur, l'étendent, l'enrichissent, et, en définitive, préparent d'autres lectures" (9).

Bref, cette large sociabilité de la lecture et par la lecture

"peut être considérée comme le facteur le plus déterminant dans la constitution de l'horizon d'attente dont chaque lecteur se dote pour recevoir les textes qu'il lit et pour les comprendre, c'est-à-dire leur construire un sens partageable avec son temps et son espace social de référence" (10).

$C^{\prime}$ est cet horizon d'attente qui est à prendre en compte (lectures $d u$ quartier) et à travailler (lectures au quartier) si l'on veut développer les formes écrites de la Culture dans les groupes sociaux dominés.

On comprend que dans cette perspective l'analyse interne et formelle ne puisse rendre compte de manière satisfaisante des difficultés de lecture ou du peu d'appétence à la pratique régulière et comme spontanée de la lecture, de certaines lectures. En fait l'enjeu pédagogique véritable est bien sûr d'améliorer mais surtout de transformer une compétence technico-scolaire en pratique culturelle régulière, bref de produire un habitus lectural. Voilà ce que pour nous lire veut dire.

L'expérience et les réflexions dont nous allons faire ètat ont pour contexte un environnement familial et social où précisément on lit peu (et selon des modes spécifiques) ou pas.

\section{UN QUARTIER, UN COLLĖGE, UNE ÉQUIPE.}

Le collège où nous travaillons, se situe dans la zup des Minguettes, banlieue qui a fait l'objet d'une littérature journalistique abondante sinon éclairante. $C^{\prime}$ est le plus grand ensemble de logements sociaux de l'agglomération lyonnaise et également un des plus importants au niveau national. La composition sociale de cette ville réunit par ailleurs "tous les critères d'une population défavorisée".

(8) A. Ernaux, La Place, Gallimard, 1983, p. 80

Nous illustrerons notre propos de citations extraites de ce roman non seulement parce que la sobrieté dramatique de l'écriture nous plaît mais encore parce que l'auteur, une collègue, decrit son acculturation. les écueils rencontrés, les tensions supportées, les ruptures et les déplacements accomplis tout au long de son cursus. Or. bien que le problème soit ancien il est symptômatique de constater que les problèmes posés par "l'articulation entre la culture d'origine d'un milieu social déterminé (autochtone) et celle que véhicule le système scolaire ont fait l'objet de très peu de travaux". (Ph. Longchamp. Culture/Cu/tures, in Le Français aujourd'hui, no 70,0 . 6).

(9) J. Hébrard, op. cité, p. 416

(10) idem, ibidem. 
Les Minguettes, construites sur un site de 220 hectares dominant la vallée du Rhône et ceinturé d'usines (R.V.I., Sigma-Diesel, Rhône-Poulenc...), se présentent comme une mosaïque de quartiers. Entre 1967 et 1975, 130 bâtiments dont 62 tours de 15 étages ont été livrés. Sur les 9100 logements, $80 \%$ sont des logements H.L.M. locatifs, $16 \%$ sont des logements en copropriétés et habités par leurs propriétaires. On ne trouve donc pratiquement que des immeubles collectifs ( $4 \%$ d'individuels seulement). Ces logements récents sont en majorité de taille moyenne et bien équipés. Par contre "les possibilités d'accueil dans les services collectifs administratifs et sociaux sont faibles" (11). II n'y a par exemple qu'un seul gymnase pour 13 établissements scolaires. Malgré un niveau d'équipement important, la vie culturelle se trouve "entravée par le manque de salles de spectacles et de bibliothèques, en particulier pour les enfants; la faible diversification des équipements ne permet pas de répondre à l'évolution de la demande venant des publics hors vie associative, des groupes d'enfants des quartiers, des jeunes, des parents isolés..." (12). La concentration de l'habitat et l'isolement des habitants coupés de la vieille ville et des zones d'emplois pourtant proches font de la zup "un monde à part".

Dans ce quartier de 25000 habitants, près de $40 \%$ des personnes sont d'origine étrangère et parmi celles-ci $60 \%$ d'origine maghrébine. Quarante nationalités sont présentes sur la zup qui malgré tout se dépeuple (2000 personnes en moins par an) et se vide (près de $25 \%$ du parc immobilier est inhabité), bien que le nombre de personnes chez les ménages étrangers soit très élevé 15,1 contre 2,2 en moyenne à Lyon). Globalement entre 1975 et 1982, 20000 personnes ont quitté la zup pendant que 7600 emménageaient: c'est dire que la vie sociale des quartiers est frappée de précarité même si les ménages nouvellement arrivés sont en grande partie des ménages d'ouvriers et que la stabilité est relativement plus grande chez les étrangers.

La population des Minguettes est jeune : les moins de 25 ans (pour la plupart jeunes immigrés de la seconde génération) représentent $56 \%$ de la population et la moitié des habitants a moins de 22 ans. Actuellement ce sont les adolescents qui sont les plus nombreux.

II convient de compléter ce rapide descriptif de la réalité urbanistique et de ses caractéristiques démographiques par un résumé de la situation socio-économique. Les catégories socio-professionnelles les plus importantes sont celles des ouvriers et des employés, masse de salariés subalternes qui représentent $84 \%$ des actifs. Les ouvriers représentent $44 \%$ de la population salariée (35\% en Rhône-Alpes) et se répartissent également entre ouvriers qualifiés (ajusteurs, monteurs, conducteurs d'engins de transport...) et ouvriers spécialisés-manœuvres. Dans la population étrangère le pourcentage d'ouvriers atteint $74 \%$ mais les ouvriers spécialisés-manœuvres sont plus nombreux que les ouvriers qualifiés.

Les employés sont nombreux eux aussi ; ils représentent $40 \%$ de la population salariée (26 \% en Rhône-Alpes); les $2 / 3$ sont des femmes (secrétaires, employé(e)s de commerce, personnels de service, agents hospitaliers). Le taux d'activités est plus élevé que la moyenne régionale (une deuxième personne travaille dans 8 ménages sur 10 chez les ouvriers). Mais en même temps le taux de

(11) M.-P. Ambrogelly et M.-H. Farrouch, Vénissieux: les Minguettes, qui habitent la ZUP? in Points d'appui pour l'économie Rhóne-Alpes, no 25, Octobre 1983, pp. 7 a 38.

(12) idem, ibidem. 
chômage est très fort: il atteint $19 \%$ pour les "étrangers" et $30 \%$ chez les jeunes de 16 à 25 ans. En outre, $68 \%$ de cette tranche d'âge ne suit plus aucun enseignement, même si l'abandon du système éducatif est moins précoce chez les filles. La part des diplômés est en diminution par rapport à 1975 mais le niveau des diplômes est plus haut qu'en 1982. En ce qui concerne la population totale, la moitié des personnes de plus de 17 ans habitant aux Minguettes n'a aucun diplôme, ce qui n'est pas sans répercussion sur la pratique générale de la lecture, lecture dont on sait qu'elle est "très liée à l'appartenance socio-professionnelle et au niveau d'études" (13).

Notre collège recrute donc essentiellement et de plus en plus dans les couches populaires, immigrées ou non, si bien que sur 760 élèves inscrits, 280 sont d'origine étrangère (ou étrangers), 30 proviennent des D.O.M.-T.O.M. et $50 \%$ sont boursiers $(20 \%$ de familles sont sans revenus officiels, une famille sur deux est confrontée au chômage, les cellules familiales sont souvent disloquées).

L'échec scolaire est la règle plus que l'exception. Bornons-nous à quelques chiffres particulièrement significatifs : à la rentrée 1984, 1/3 seulement des élèves

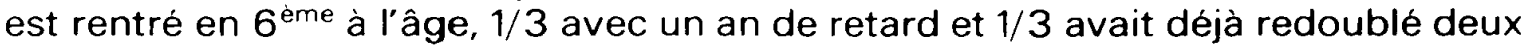
fois dans le cycle primaire. Si l'on retient comme critère pertinent de réussite scolaire l'orientation non contrainte et l'accès à une classe de seconde, on constate tout au long du cursus en collège une déperdition dramatique des effectifs : soit une cohorte de 270 élèves qui entre en $6^{\text {eme }}$ en 1980,125 passent en $4^{\text {eme }}$ et 50 seulement accède au lycée en 1984. C'est dire que moins de $10 \%$ obtiendront un bac contre près de $30 \%$ en moyenne pour une classe d'âge, au niveau national.

On aura garde de ne pas oublier que la réalité scolaire n'épuise pas la réalité sociale des apprenants. Mais il est mal-aisé d'évaluer précisément le nombre de parents analphabètes, illettrés (14) et/ou non francophones; il est également difficile de saisir véritablement jusqu'à quel point le processus de scolarisation, court ou long, fait partie de l'horizon culturel "spontané" de familles; il est complexe enfin dans une pédagogie traditionnelle de type transmissif de cerner les traits qui structurent la culture de nos élèves (culture d'origine pour certains, culture scolaire, culture de classe, culture de masse). Or, peut-on se permettre d'ignorer que compétences culturelles, perspectives et espérances scolaires, système(s) culturel(s) modèlent toute communication culturelle, à l'école comme ailleurs?

En tout état de cause, pour le problème qui nous intéresse, les difficultés se manisfestent spectaculairement par des refus de lecture dans des conditions et des protocoles "classiques", par des lectures besogneuses sans réel profit, enfin par des lectures marginales, parallèles, souterraines. II va sans dire que ces comportements contradictoires de lecteur peuvent animer des élèves différents au même moment et le même élève à des moments différents.

C'est par un travail d'équipe que la communauté éducative essaie de répondre aux problèmes des apprentissages notionnels et relationnels. Ces équipes sont réunies sur la base d'une politique pédagogique qui vise à intégrer socialement sans désintégrer culturellement. "Un certain type d'ouverture sur

(13) Des chiffres pour la culture. Ministere de la Culture, 1980, p. 158

(14) Voir les mises au point de J. Dumazédier et H. de Gisors, "Français : analphabètes ou illettrés". Revue Française de Pedagogie, no 69, 1984, pp. 13 à 20 et J. -F. Laé et P. Noisette : "Je, tu, il, elle apprend ; étude documentaire sur quelques aspects de lillettrisme". La Documentation Française, Collection "Documents, Affaires Sociales", 1985 
le quartier" est le point d'appui de plusieurs actions concertées : celles de l'animateur qui travaille à mi-temps sur le quartier et à mi-temps sur le collège, celles de l'assistante sociale, celles des intervenants (enseignants volontaires, parents, anciens élèves, travailleurs sociaux) au "lieu a(p)prendre" qui, hors cadre scolaire, offrent aux élèves une assistance méthodologique et psycho-pédagogique, celles de nombreux P.A.E. enfin.

La quasi-totalité des professeurs de français décident, dans le cadre d'un P.A.E. "Lire-écrire") d'abandonner les pratiques scolaires de lecture les plus sclérosées (et les plus élitistes) pour imaginer un enseignement plus satisfaisant qui prenne en compte, pour la travailler, la réalité culturelle globale des jeunes lecteurs.

Le groupe s'organise en fonction de cet objectif commun. Il est clair cependant que les modalités d'implication de chacun dans le projet sont inégales et diverses, que les compétences théorico-pédagogiques sont différentes et variées. Nous nous retrouvons d'abord en petit séminaire de lecture/écriture pour à la fois donner corps à l'équipe et mieux connaître nos propres pratiques culturelles (15). La micro-analyse de nos comportements personnels s'avère passionnante mais aussi d'un réel profit pour le groupe; l'abandon de la position magistrale (nous lisons et écrivons sur des consignes communes et pour des communications croisées) et l'effacement allègre du prétendu individualisme professoral dynamisent l'équipe.

Nous nous inscrivons ensuite à des stages de formation continue où le groupe acquiert un ensemble de reférences théoriques communes. Nous nous réunissons, enfin, tout au long de l'année (16) pour programmer le travail pédagogique (répartition des tâches, harmonisation des méthodes et des contenus par niveau, calendrier du projet...). Ces réunions qui sont des moments de régulation, d'évaluation et de décision, sont aussi des moments d'information: un sousgroupe a régulièrement la responsabilité d'une mise au point théorique imposée par le projet en cours. Ce dispositif nous intéresse dans la mesure où il permet d'activer chez chacun la recherche théorique en liaison avec les difficultés concrètes précises et locales. La mise en œuvre d'un projet d'ouverture coopérative avec le quartier suppose l'abandon des manuels ou livres de lecture auxquels on préfère des lectures de livres selon des modes moins scolarisés, comme on va voir.

\section{DES RELATIONS LECTURALES A CONSTRUIRE.}

Les activités de lecture (-écriture) sont trimestrielles; elles concernent aussi bien les $6^{\text {ème }}$ que les $3^{\text {ème }}$, les C.P.P.N./C.P.A. que la petite classe de germanistes/latinistes. Dans son principe, cette unanimité n'est pas démagogique et ce pour deux raisons. Chaque classe a la latitude de définir un projet spécifique à l'intérieur du projet collectif ; les lectures transversales, de classe à classe et de collège à quartier, tendent à modifier les représentations lecturales très marquées scolairement et socialement.

(15) H. Hamoñ et P. Rotman, "Coupures. Culture jeune - culture prof... ", in Tant qu'ily aura des profs, ch. 7, pp. 303 à 314. Editions du Seuil, 1984

(16) Grâce aux financements P.A.E., les réunions sont payées en heures à taux spécifiques; de son côtél'administration du college dégage plusieurs demi-journées prises sur notre temps d'enseignement. 
Le projet du premier trimestre consiste à publier une plaquette de poèmes. Le haîku, poème japonais, a été choisi pour sa brièveté : un texte court et sémiotiquement point trop complexe facilite l'entrée collective en lecture/écriture. Les caractéristiques linguistiques et rhétoriques du genre permettent des apprentissages liés au programme officiel. De plus, dans son contexte original (le Japon, du $X V I^{e m e}$ à nos jours), ce flash poétique est calligraphié verticalement sur de délicates banderoles suspendues dans les maisons, discrètement offert à la lecture familiale. C'est ce trait culturel - le haiku comme forme de lecture domestique qui sera conservé puisque les poèmes-affiches de chacun et une anthologie des meilleurs textes seront rapportés chez soi. C'est enfin en raison de son exotisme culturel que le haîku nous a intéressés. Cet intérêt n'est pas contradictoire avec le souci de prendre en compte les connaissances et reconnaissances culturelles de nos élèves. Pour éviter l'ethnocentrisme spontané du professeur de français (17) et ne pas privilégier une communauté culturelle, nous avons délibérément choisi de travailler une tradition poétique vivante et que personne ne pouvait revendiquer d'entrée de jeu.

Le riz une fois récolté
l'épouvantail
n'est plus le même
BUSON

\author{
Tous les divers \\ les difficiles noms \\ des herbes folles du printemps \\ SHADO
}

\section{la laisser quel dommage! \\ ah cette violette!}

La cueillir quel dommage!

NAOJO (18)

Tout d'abord des haïkus nombreux sont lus aux élèves, puis découpés ; chaque phrase inscrite sur une bandelette de papiers, ils sont distribués. En petits groupes, on lit ces fragments et on essaie de les combiner pour reconstituer de nouveaux haïkus. Chacun lit ses trouvailles. C'est un premier contact avec le poème. Personne n'a encore écrit mais en lisant et en utilisant la mobilité du puzzle poétique, des centons ont été produits.

Dans un deuxième temps, un texte est distribué (textes romanesques contemporains). II s'agit, cette fois, de lire et de sélectionner, avec un crayon, selon le principe du caviardage, on élimine des mots pour ne garder que les seuls syntagmes susceptibles de constituer un haïku. II est bien évident que ces travaux se sont accompagnés de nombreux retours aux poèmes d'origine et ont permis de dégager les règles du genre ( 3 phrases exprimant une sensation, la toute première impression, un vocablaire simple et concret...).

Enfin, les élèves ont pris une page blanche pour écrire mais la réalité rurale du Japon avec ses papillons, ses rizières, ses grenouilles aurait fait s'enliser les stylos dans la guimauve des ciels bleus et des soleils d'or.

En effet, il n'était pas souhaitable de chercher à imiter la cosmicité quotidienne qui fait du haîku un exercice scripto-spirituel, mais, dans un mouvement d'appropriation critique, de parler le quartier, de parler au quartier en donnant à lire la réalité de la zup de tous les jours.

(17) Pour une approche plus fine. voir L. Demailly. "Diversités des pratiques pedagogiques", in Pratiques no special Collque de Cerisy. pp. 23 à 34 ou du même auteur. "Contribution à une sociologie des pratiques pedagogiques". in Revue francaises de sociologie, 1984. pp. 96 à 119

(18) Deux livres sur lesquels nous avons travaille: P. Seghers, Livre d'or du Haikaï, Robert Laffont, 1984 et Haiku (pré face de $Y$. Bonnefoy). Fayard, 1978. 
Toit là-haut

au-dessus des tours

oiseau de Monmousseau

Le soir tombe

les trottoirs de la division Leclerc

le pas des gens

Avenue Jean Cagne

ciel gris comme le bitume

couleur des immeubles

Regard avide

au marché du samedi

un chômeur

Le lycée bleu

les élèves arrivent

dans le matin sombre

\author{
Des portes ouvertes \\ des magasins illuminés \\ Noël à Vénissy \\ Les passants rares \\ bruits sur les pavés mouillés \\ couvre-feu ordinaire \\ Immeubles de béton \\ draps bleus aux fenêtres \\ caresses sur les murs \\ La feuille est là \\ le stylo aussi \\ moi je n'y suis pas \\ Au bas des tours \\ leur radio sur l'épaule \\ les jeunes
}

\author{
Devant cet arrêt \\ mon 36 quotidien \\ odeurs pesantes d'Elf
}

Après le travail sur le haïku, nous abordons un autre genre court, le proverbe. A l'inverse du haïku, la production proverbiale est à la fois immémoriale et transculturelle. C'est pourquoi, cette fois, les élèves peuvent être mis en position de recherche active pour constituer le corpus sur lequel ils vont réfléchir. La collecte de proverbes vivants (connus sinon utilisés) se fait auprès des parents ou autres personnes du quartier. Ainsi au lieu de recevoir un ensemble de textes préétablis, pré-découpés et souvent déconnectés de leur actualité socio-affective, les apprenants sont placés dans une situation d'intermédiaires culturels. Le jeune créole, la jeune malgache, le jeune tunisien ou la jeune lyonnaise lisent et commentent tour à tour à la classe et au professeur les résultats de leurs recherches. Ce travail de parémiologie (l'étude des proverbes) comparée met en évidence les invariants structuraux (structures phoniques, rythmiques, grammaticales, stylistiques, phrastiques, logiques, génériques) et fonctionnels du genre proverbial. Ces invariants et notamment l'oralité et l'anonymat, typiques de ces formes discursives, donnent aux élèves une sécurité culturelle inhabituelle en classe de français et relancent la quête auprès des familles dont les savoirs populaires sont ainsi pratiquement et pédagogiquement valorisés.

Une fois la dimension transculturelle démontrée et éprouvée, les élèves ont plaisir à expliquer les connotations culturelles qui font dire à Nîmes"Le mortier sent toujours l'ail "et à Dieppe "La caque sent toujours le hareng ", au Congo "Le poisson nkanki n'avale pas le crocodile, le crocodile n'avale pas le poisson nkanki" et en Europe "Les loups ne se mangent pas entre eux". II apparaît que l'ensemble de la communauté locale est porteuse de savoirs in-ouïs et pourtant disponibles et utiles. Dans le va-et-vient école/quartier, l'élève à la recherche de proverbes, peut recueillir partie de son matériau aussi bien auprès de son professeur de math, du principal, de l'agent de service (...) que de ses parents ou de ses voisins. Le profit symbolique est double et réciproque : la communauté éducative se désacralise, la famille et le quartier se valorisent. Dans une interaction réciproque les deux partenaires tendent à se rapprocher, la distance culturelle à diminuer.

L'ensemble de ces dispositions permet d'établir des relations lecturales moins rares et moins artificielles que d'ordinaire, où la seule et éventuelle bonne volonté culturelle trouve son compte. Prenons deux exemples: 
Telle classe de $3^{\text {eme }}$ décide de lancer un grand jeu concours "Prixverbes".

Le questionnaire, fragment retravaillé de la culture proverbiale du quartier, socialise les acquis scolaires et sollicite à l'extérieur des lectures attentives (version moderne de la veillèe des chaumières?) et des discussions d'ateliers comme chez R.V.I. où le père d'une des élèves a mis à contribution ses collègues de travail pour répondre aux questions (ouvriérisme impénitent?).

Toujours dans la perspective d'établir des relations multiples et diversifiées, les boîtes-réponses étaient disposées à la loge du collège et dans un magasin de fripes de la très passante galerie marchande du quartier. On pourrait schématiser ainsi les réseaux de communication parcourus à partir de cette activité choisie à titre d'illustration.
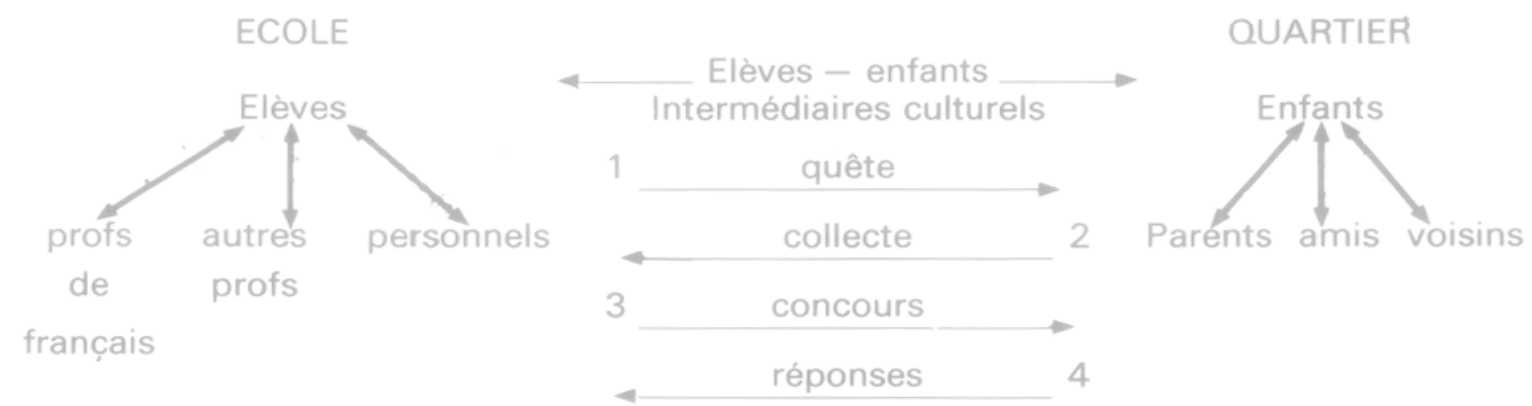

Autre exemple, des élèves de sixième se proposent d'expliquer, selon le principe des contes de la St Glinglin, l'origine imaginaire d'un proverbe de leur choix. Ces petits textes réunis en édition "Pocheverbes" sont proposés à la lecture du public.

L'expérience acquise nous permet d'être plus ambitieux pour la fin de l'année. Les haîkus et les proverbes n'avaient occupé qu'une partie du temps d'enseignement, chaque classe et chaque porfesseur ayant eu la latitude de moduler son engagement et l'ampleur de son projet.

L'écriture individuelle ou en petits groupes de micro-romans va mobiliser cette fois toutes les heures de cours; ce travail d'écriture mi-longue (et de réécriture) touche en effet à tous les apprentissages requis (de l'orthographe à la grammaire de textes, sans oublier l'histoire littéraire). Le plus souvent les élèves optèrent pour une fiction "urbaine", un conte, une petite nouvelle ou un véritable micro-roman sur "leurs" Minguettes. II s'agissait, en effet, d'opérer une prise d'écriture personnelle sur une réalité quotidienne si spectaculairement médiatisée. La motivation a été relancée par la certitude que tous ces récits seraient lus par des lecteurs nombreux et divers. II fallait donc faire la conquête d'un public élargi et non plus se contenter de la correction unique et institutionnelle du professeur de lettres (19). Dans ces conditions, en effet, les jeunes scripteurs(es) jouent leur image et éprouvent la nécessité de construire leurs textes en tenant compte des lecteurs à venir. Pour maîtriser une telle situation de communication, complexe, les élèves ont besoin de techniques scripturales explicites, exigées par la tâche et non plus programmées a priori. Par exemple, les règles d'écriture de la description ne sont pas l'objet d'un apprentissage coupé de la pratique mais elles sont requises par la logique du projet : comment écrire ses Minguettes sans, d'une manière ou d'une autre, les décrire? 
Ce type de démarche suppose chez les professeurs des travaux en sousgroupes qui visent, en retombée de lectures théoriques, la fabrication de panneaux mobiles; ils exposent dans un langage et une perspective adaptés aux élèves quelques règles majeures d'écriture (macro-structuration, topoî d'ouverture et de fermeture, typologie des langages, métaphorisation... (20)). La narratologie permet de jeter les bases d'un véritable dialogue pédagogique et le travail de relectures-réécritures critériées est enfin possible, et fructueux. L'activation de compétences discursives et communicationnelles trouve là un terrain relativement solide. Ces pratiques supposent (et témoignent) qu'une pédagogie de l'écriture et de la lecture peut être construite autrement que sur le goût, le don, l'implicite, la Culture.

Ce serait en effet tomber dans le panneau que de travailler avec ses élèves en fonction des caractéristiques socio-culturelles et socio-affectives du lectorat sans, dans le même temps, tenir compte des référents culturels qu'affectionnent ces mêmes élèves. Ainsi on préférera aborder les problèmes d'écriture de l'incipit par la lecture des premières pages de romans populaires contemporains. La valise en carton de Linda de Suza sert, par exemple, de modèle pour une ouverture en flash-back. Nous avons constaté que le recours à la paralittérature (21) familière aux élèves (feuilletons, films T.V. font aussi l'affaire) donne crédit à des procédés rhétoriques qui, pris d'entrée et uniquement dans la littérature légitime, leur paraissent artificiels et gratuits. $\mathrm{Si}$, à une autre étape, on doit montrer que la poétique du texte procède par projection des paradigmes (phoniques, rythmiques, syntaxiques, thématiques...) sur les syntagmes, il sera pédagogiquement plus efficace d'analyser le tube de l'été à venir "Vacances, j'oublie tout "qu'une page de Chateaubriand dont la prose n'est pas pour autant exclue du cours (22). Les élèves sont aussi amenés à multiplier les lectures sélectives de livres : à un moment donné, tel élève aura pour unique perspective de lecture, le repérage du type d'intrigue susceptible d'être réutilisée dans son micro-roman, à un autre moment tel autre élève (ou le même) aura besoin de "balayer" une fiction pour comprendre comment est maîtrisée la notion de point de vue.

(20) Notre ouvrage de référence a été Pour lire le roman de J.-P. Goldenstein. Duculot, 1983

(21) Voir Pratiques no 50

(22) Nous pensons que dans l'histoire personnelle de chaque lecteur, comme dans la pratique pédagogique. c'est dans la confrontation/substitution de textes de statuts culturels differents que se construisent et s'aftinent en fait les compétences générales de lecture. Voir Y. Reuter. "Les parahittératures: problèmes théoriques et pédagogiques, in Pratiques no 50 et $Y$. Reuter. Pour une analyse institutionnelle de la litterature, these d'Etat, Paris XIII, 1985 
Ce travail d'écriture se clôt par une évaluation de chaque élève sur son propre texte. La grille utilisée recense les points qui ont fait l'objet d'apprentissages systématiques.

GRILLE D'ÉVALUATION

Titre du micro-roman

classe

Nom:

\begin{tabular}{|c|c|c|c|c|}
\hline $\begin{array}{c}\text { Techniques } \\
\text { d'écriture }\end{array}$ & $\begin{array}{l}\text { Type ou } \\
\text { exemple }\end{array}$ & Page & $\begin{array}{c}\text { Appréciation } \\
\text { élève }\end{array}$ & $\begin{array}{c}\text { Appréciation } \\
\text { professeur }\end{array}$ \\
\hline \multicolumn{5}{|c|}{$\begin{array}{l}\text { Mode } \\
\text { d'introduction } \\
\text { (incipit) }\end{array}$} \\
\hline \multicolumn{5}{|l|}{ Description } \\
\hline \multicolumn{5}{|l|}{$\begin{array}{c}\text { Tissage } \\
\text { (23) }\end{array}$} \\
\hline \multicolumn{5}{|l|}{ Rythme } \\
\hline \multicolumn{5}{|l|}{$\begin{array}{c}\text { Narrateur } \\
\text { et } \\
\text { Point de vue }\end{array}$} \\
\hline \multicolumn{5}{|l|}{$\begin{array}{c}\text { Type } \\
d^{\prime} \text { intrigue }\end{array}$} \\
\hline \multicolumn{5}{|l|}{$\begin{array}{l}\text { Analyse } \\
\text { structurale }\end{array}$} \\
\hline \multicolumn{5}{|l|}{$\begin{array}{l}\text { Type de } \\
\text { clôture } \\
\text { (fin) }\end{array}$} \\
\hline \multicolumn{5}{|l|}{$\begin{array}{c}\text { Idée } \\
\text { dominante }\end{array}$} \\
\hline Langages & & & & \\
\hline
\end{tabular}

On observe que sur la même grille, le professeur évalue lui aussi le travail. A partir de ce moment-là les textes vont quitter la classe et affronter les comités de lecture. Il y a deux types de lectorat : un lectorat interne au collège et un lectorat extérieur. Le premier concerne essentiellement les élèves qui ont à lire et à classer une douzaine de récits photocopiés (24). Les échanges se font sur un même niveau (ex.: $6^{\text {ème }} 1,6^{\text {ème }} 2 ; 4^{\text {ème }} 3,4^{\text {ème }} 4$ ). Chaque élève lit tous les textes

(23) On entend par "tissage" ce que J. Ricardou appelle "ecriture effervescente". Voir Pratiques no 20.

(24) Les credits P.A.E. permettent d'assurer les frais de reproduction necessaire à la circulation rapide et simultanée des micro-romans parmi les divers lecteurs. 
proposés en classe, à l'issue d'un débat, établit un classement général. Ces lectures sont dans les meilleurs des cas des temps très forts d'apprentissage car les élèves sont placés devant des textes non sacralisés dont ils connaissent, par expérience, les processus de production. En effet, ils en ont largement éprouvé les contraintes et/ou apprécié (éventuellement !) l'intérêt. Aussi peuvent-ils argumenter leur lecture en connaissance de cause même si la maîtrise du discours critique est loin d'être assurée d'emblée.

Les textes circulent aussi parmi les enseignants volontaires: le professeur de sciences physiques de $5^{\text {ème }} 1$ lit les textes écrits par ses $5^{\text {èmes}} 1$; le personnel du collège est également sollicité.

Mais ce qui va donner aux écrits toute leur dimension sociale, c'est d'être soumis à la lecture critique du quartier. La lettre suivante est alors largement diffusée dans le collège et auprès des parents.

Collège P. ELUARD

$P A E$ Lire-Ecrire

A tous les parents d'élèves,

A tout le personnel du Collège,

Je vais vous raconter l'histoire des élèves du Collège Paul Eluard. Vous la connaissez déjà un peu. Vos enfants, vos collègues, vos voisins, vos amis vous en ont déjà parlé.

Au premier trimestre, ils avaient inventé, écrit, affiché des haikus; au second, des proverbes.

Cette fois, ils se sont lancés dans des textes beaucoup plus longs. I/s ont raconté des histoires drôles et tristes, quotidiennes et extraordinaires; des histoires de la ZUP. Celle qui existe "pour de vrai", celle qui existe "pour de rire", celle dont on rêve qu'elle existe et celle qui existera peut-être un jour.

Le but? // est toujours le même: faire lire leurs productions par d'autres que leur "prof", par le plus possible de monde, par tous.

Mais on ne pouvait pas, comme pour les textes précédents les faire connaitre par voie d'exposition ou d'affichage. Alors l'idée d'un jury de lecture est née.

Chaque classe produirait environ 12 textes qui seraient lus par un jury constitué comme suit: 6 parents, amis, voisins, 2 enseignants, 1 agent administratif (+ 4 élèves délégués par classe).

Vous faites forcément partie d'une des trois catégories citée: pour faire partie du jury, il suffit de savoir lire, même si vous n'en avez pas trop /'habitude, même si vous n'aimez pas tellement ça.

Puis parmi les 12 textes de la classe dont vous serez le lecteur (du 29 mai au 9 juin) il vous faudra choisir le texte que vous aurez préféré (parce qu'il vous aura fait rire, parce qu'il vous aura fait rêver, parce qu'il vous aura ému ou pour n'importe quelle autre raison).

Le jury se réunira (entre le 10 et le 15 juin) et on élira le meilleur texte.

Enfin, les textes choisis seront soumis à un second jury de lecture dans l'espoir d'être publiés dans un journal (les classes ont envoyé des courriers). 
Alors, si vous avez envie de lire les textes du Collège, si vous avez envie de connaitre sur la ZUP des histoires moins banales, il vous suffit de remplir et de retourner le petit bon ci-joint.

\section{FEREZ-VOUS PARTIE DE L'AVENTURE?}

Près de 130 adultes (personnel du collège et surtout parents, voisins, copains, anciens élèves...) acceptèrent nos propositions efficacement relayées par la F.C.P.E., la C.S.C.V., I'I.F.R.A. (25) et les travailleurs sociaux. Toutes ces personnes constituent des groupes qui se répartissent la lecture des micro-romans produits dans les différentes classes. A l'intérieur de ces groupes, le lectorat du quartier est toujours majoritaire ( 6 sur 10, les 4 élèves délégués représentant "la " voix de leur classe). Bien souvent les lecteurs extérieurs sont des parents ou des proches des élèves de la classe. Ce n'est que trop rarement, faute de temps, que ces jurys de classe rencontrent directement les élèves-scripteurs pour discuter avec eux de leur travail dans un échange mutuellement profitable. La réunion générale de tous ces jurys de classe rassemble plus de 60 personnes; un long débat s'instaure pour apprécier les qualités des meilleurs récits. Dans ce cadre-là les critères d'évaluation avancés sont moins techniques que ceux des élèves mais, complément attendu, souvent plus réactifs et plus impressionnistes. La discussion est sereine, riche et animée : certes le lectorat est pluriel mais il n'est pas disparate car il vit et/ou travaille sur ce quartier raconté. On notera que si sur plus de trois cents textes, quinze seulement sont sélectionnés pour publication, le dispositif général de lecture mis en place assure à tous les écrits plus de trente lecteurs de compétences et de statuts divers.
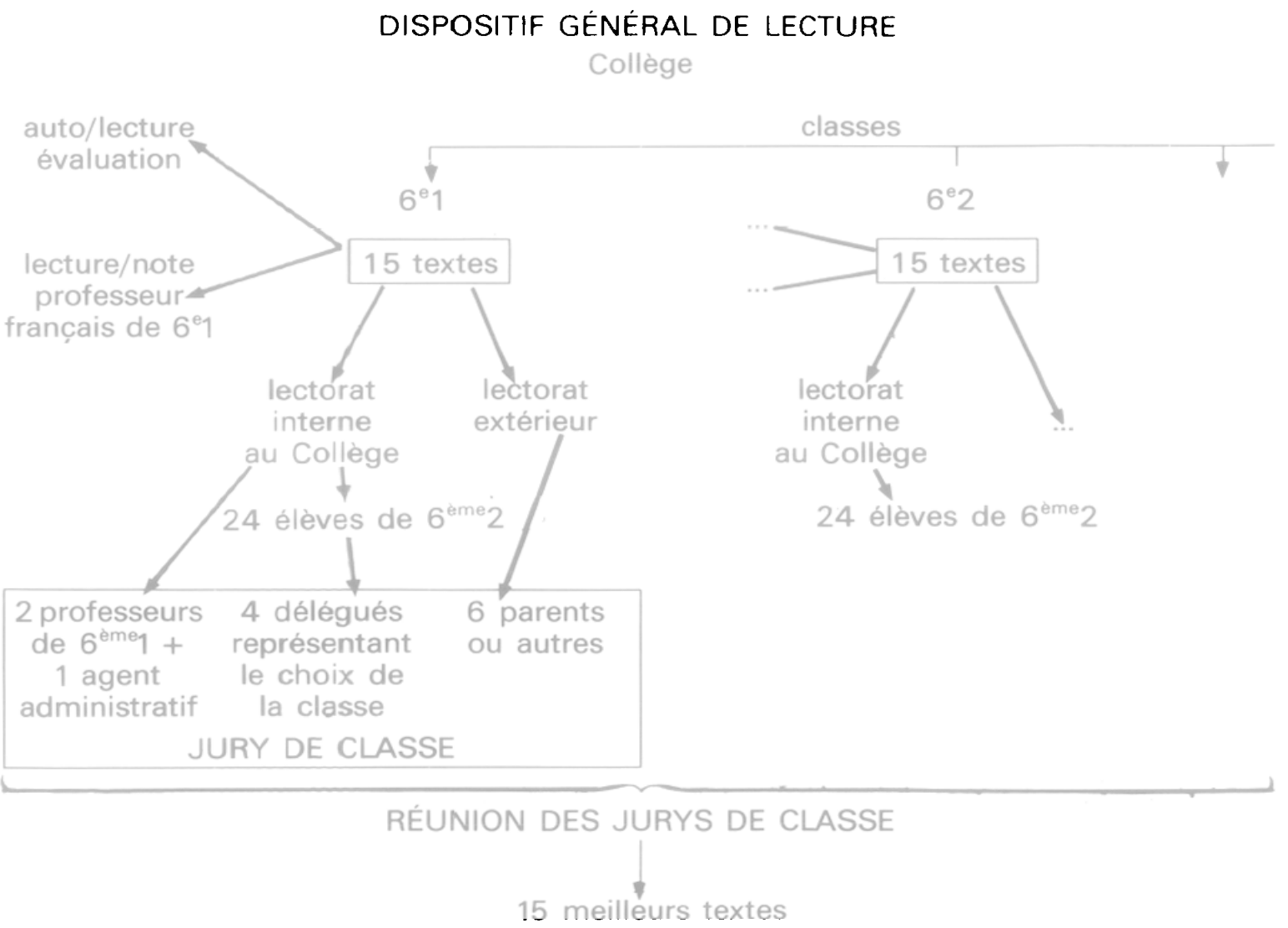

(25) F.C.P.E. : Fedération Cornec des Parents d'Eleves; C.S.C.V: Confédération Syndicale du Cadre de Vie; I.F.R.A. : Institut de Formation Rhóne-Alpes qui organise des stages de formation continue auprès des agents culturels engagés dans la lutte contre l'illettrisme. Le siege de I'I.F.R.A. est proche du college. 
Le retentissement de ces comités de lecture est certain. Pendant les travaux d'écriture, les élèves, dans leur majorité, font un effort réel pour soigner la lisibilité de leur texte. Les plus jeunes sollicitent les aînés pour dactylographier leurs micro-romans, les plus grands utilisent parfois les machines à écrire mises à leur disposition dans les centres sociaux. Lors des lectures, il est arrivé qu'au marché un collègue de français soit questionné par des lecteurs sur le déroulement des opérations ou qu'à la sortie du collège un élève impatient demande à une mère-lectrice ce qu'elle pense de son histoire...

Outre ces témoignages anecdotiques, un questionnaire-bilan à la rentrée suivante indique clairement que l'ensemble du lectorat a apprécié cette possibilité de participer à l'action éducative. Certaines personnes ont lu par plaisir jusqu'à quarante textes et plusieurs assurent que cette lecture a changé leurs relations avec leurs enfants. Bien souvent elles se déclaraient surprises par ce que "les jeunes" étaient capables d'écrire et par ce qu'ils racontaient des Minguettes. De leur côté, les élèves qui, par lettre interposée, avaient la charge de contacter leurs futurs lecteurs furent amenés à considérer que la lecture pouvait être l'affaire de tous. Ainsi, nous le soulignons, les situations techniques d'apprentissage évitent le technicisme parce qu'elles sont appelées par des situations socio-scolaires de communication. L'idée du lectorat de quartier voulait répondre à cette double exigence pédagogique (26) en faisant jouer à son profit les réseaux " souterrains " de circulation des imprimés. Les grands ensembles, en effet, voient se restructurer peu à peu "de nouveaux réseaux d'échange et d'entraide "(associations et voisinages) (27) ; la réalité de ces quartiers est donc qu'ils sont des "lieux de conflits mais aussi de solidarité "(28), le support privilégié des pratiques populaires quotidiennes (29). La grand partie des matériels de lecture parcourt ainsi, dans ces groupes en quête de sécurité culturelle et d'échanges conviviaux, des "canaux informe/s tracés le plus souvent par les relations affectives, (...) et souvent amicales" (30).

Les jurys de quartier permettent, réduisant la distance pratiques scolaires/pratiques sociales, de mettre à profit des interrelations originales que l'école a depuis longtemps ignorées en monopolisant les processus d'apprentissage lecturaux.

En somme, l'ambition des jurys de quartier est d'intégrer les relations socio-affectives dans une pédagogie plus englobante pour changer les pratiques de lecture (écriture) et au moins l'image que s'en font les familles, en un mot pour travailler l'habitus lectural.

Nous ne voudrions cependant pas laisser croire à un succès exemplaire. Même s'il faut tenir compte du contexte difficile dans lequel nous travaillons (chômage, double journee de travail, mères seules, familles nombreuses, illettrisme...) les résultats sont à modaliser. Tout compte fait, un quart des familles au plus a répondu à notre appel et il faut souligner que les lecteurs volontaires ont été féquemments des lectrices, des lectrices de culture française. Souvent, par ailleurs, ces personnes étaient membres d'associations intéressées à la vie du quartier.

(26) A. Pëtitjean. "Apprentissage de l'écriture et travail en projet". in Etudes de linguistique appliquée, no 59, sept. 1985, pp. 88-101.

(27) M. Verret, L'espace ouvrier, collection U Armand Colin 1979,p. 151

(28) $\mathrm{H}$. Dudebout, Ensemble, refaire /a ville, La Documentation Française, 1983, p. 57

(29) P. Mayol, "Habiter". in L'invention du quotidien, tome 2, Coll. 10/18, pp. 13 a 146

(30) N. Robine, Les jeunes travailleurs et la lecture, La Documentation française, 1984, p. 117. 
En règle générale, les critères de sélection traduisaient des représentations socio-culturelles dominantes dans les classes populaires : survalorisation de la norme orthographique, de la correction linguistique, prime à l'écriture réaliste, aux récits courts, factuels et chronologiques, dévalorisation relative de l'originalité.

On sait aussi que dans les réseaux populaires le livre est un médium affectif (l'intérêt de l'échange est d'abord dans l'échange d'intérêts) peu verbalisé: "Lis çà, c'est chouette!". Ce rapport aux livres explique la difficulté et/ou le refus de certains élèves à "parler" leurs lectures selon les dispositions du discours savant et la gêne éprouvée malgré tout par nombre de lecteurs, potentiels ou non, alors même qu'ils déclaraient être intéressés par les pratiques de sociabilité culturelle proposées. Quelques-uns des quinze micro-romans retenus ont été publiés en partie dans quelques rares revues ou journaux locaux. Nous avions souhaité que la presse nationale si friande de "papiers" sur notre ZUP abandonne sa logique de diffusion unilatérale; nous espérions qu'une logique de la communication permettrait un renversement, même éphémère, des rôles et que les jeunes lecteurs seraient en situation d'écrire leur quartier pour le faire lire aux autres.

Voici l'un de ces textes, modeste fragment du discours minguetteux.

Micro-Roman.

Séjour noir.

A une vingtaine de kilomètres de Vienne, dans la banlieue sud de Lyon, tour $n^{\circ} 4,9^{e}$ étage, Brigitte et Alain attendent avec impatience Christine et Julien, des amis d'enfance. Malgré l'alarme posée en prévision de ce voyage, Julien craint pour sa voiture. A l'idée d'étouffement que lui inspire cette ville dépourvue d'espaces verts, où les gens fourmillent sous l'ombre épaisse des tours... En s'imaginant la démarche de ces gens vils et agressifs, Julien en a des suées.

- "Tu n'oublieras pas de prendre ton sac à main à l'arrière de la voiture, sinon tu peux lui dire adieu! Et ne fais pas cette tête là, je t'aurais prévenu! Avec tout le chómage qu'y a, y a que les ethnologues qui auront toujours du boulot! I/s doivent avoir de quoi faire avec tout ce qu'y a !".

Plus Julien parlait, plus la colère lui montait. Christine voulant détendre latmosphère:

- "Tu sais, on pourra aller à la piscine, y paraít qu'elle est ouverte!".

- "Ne compte pas sur moi, je tiens pas à revenir en maillot avec deux ou trois coups de poings dans le ventre! Quand j'y pense... Tiens voilà une bombe lacrymogène, si tu vois quelqu'un de louche arriver dans ta direction, n'hésite pas. Si tu crois que je vais me laisser faire!".

- S'il savait avec qui on va passer l'après-midi!...? Pauvre imbécile.

Puiqu'ici, c'est la loi de la jungle, laissons Tarzan nous mener parmi les fauves.

- "Christine !... A quoi tu penses?".

- "Je rêve...".

- Je me vois déjà descendre de la voiture avec Julien comme garde du corps, prêt à toute éventualité. J'imagine déjà sa démarche, les valises à l'avant en guise de bouclier. Plus que deux kilomètres...

Julien agacé par le silence:

- "T'as pas vu les nuages?".

- "Si j'ai remarqué, y'a de l'orage dans l'air...".

- "Tiens voilà la plaque: VENISSIEUX, on va pas tarder à arriver".

Après dix minutes de parcours, les voilà garés, Julien, la mine renfrognée, Christine en admiration devant les avenues fleuries et les pelouses bien tondues.

- "Tu crois pas que tu devrais desserrer le bouton de ta chemise?". 
- "Oh ca va, tu vas pas commencer".

Le beau temps semble au rendez-vous, le voyage ne s'est pas trop mal passé et pourtant Julien garde une tête de chien battu égaré qui se demande ce qu'il fait là. Dans l'ascenseur, face à un jeune homme à la carrure impressionnante, voilà Popeye en panne d'épinards.

- "Qu'est-ce qu'il fait chaud!".

La sonnette retentit. Julien a hâte qu'ils ouvrent la porte... avec la soif qu'il a. Julien prend un ton d'exagération:

- "Qu'est-ce que je suis content de vous voir: çà fait un moment qu'on s'est pas vus".

Après bien des paroles inutiles, allongé sur le fauteuil, fatigué par le voyage, Julien somnole, revoyant des séquences d'un film vu récemment, où la place du persécuté est la sienne. A son réveil, scrutant la pièce, ébloui par le soleil, il se dirige vers le balcon, complétement hébété. Tout le monde semble être sorti.

En se penchant, s'offre à ses yeux une vue panoramique. Le vert de la pelouse piqué de jaune et blanc, les arbres balancant de droite à gauche, le ciel d'un bleu uniforme où un avion dessine un grand trait blanc sur son passage... Se surprenant à apprécier les alentours, d'un froncement de sourcils, il se fait un bref rappel à l'ordre. Au bas de la tour, sous son ombre épaisse, Julien aperçoit un homme énervé, forçant la portière d'une voiture. Ni une ni deux, le voilà prêt à sortir, Julien en est soufflé:

- Et en plus, c'est un Noir!... Après on dira que je suis rac... -

Arrivé en bas, examinant l'homme et ses bras bien musclés, il décide de prendre congé avant même de lui avoir parlé.

- Voler une voiture en plein jour, décidément on aura tout vu ici! -

Le mieux à faire est de partir comme si de rien n'était. Pour peu qu'on m'accuse de complicité !...

II reprend donc sa place sur le balcon, content d'avoir surpris un voleur sous ce calme apparent. Brigitte et Christine sont de retour; il vaut mieux faire comme si de rien n'était. Heureux de constater qu'elles ramènent de quoi goûter, notre caïd engloutit son pain au chocolat sous les reproches de Christine:

- "Tu aurais pu attendre, tu sais bien que les amis d'Alain ne vont pas tarder... Tiens, j'entends l'ascenseur..."

Ouvrant la porte, Julien les fait entrer. Les regardant à deux fois. il prend un regard figé et un sourire grimaçant à la vue de ce visage noir.

- Y a pas assez de Français, faut qu'ils aillent se chercher des noirs. -

La conversation débute d'une façon toute banale, autour de la pluie et du beau temps. Julien pense systématiquement et catégoriquement à l'inverse de Yacinthe.

Puis, vient la réputation de la ville, la trop forte immigration qui selon Julien nuit au bon voisinage.

- Tu t'appelles peut-être Yacinthe, mais ça m'est bien égal. // est pourtant sympa... Je me laisse attendrir, mais celui que j'ai vu en bas volait bien une voiture ! - Yacinthe à son tour s'évade dans ses pensées:

- Je crois qu'il vaudrait mieux ne pas trop m'attarder. Je ne suis visiblement pas à ma place. Et si...? Non... Quelle importance. -

Après cette discussion café au lait, Julien se sent comme poussé par un courant, il n'écoute même plus les réponses. Puis l'homme laisse s'installer un silence pesant sous la chaleur de cette pièce où flamboient d'un noir brillant, les yeux de Yacinthe. - Quelle idée d'av... -

Julien devrait pourtant crier victoire. Au lieu de ça, la gêne prend place.

Christine fixe le verre d'eau posé contre le bord de la table et, d'un geste brusque, le pousse. Les morceaux de verre brillent sur le parquet, le silence est brisé. Le départ de Yacinthe ne tarde pas puisque prenant le prétexte de l'heure tardive, il fait ses adieux. Tout le monde est dans son coin, dans un fond de raclement de gorge, tous les regards s'évitent. Julien fixe le téléphone avec insistance. (Et bien non, il ne sonna pas!). Julien se retrouve à l'écart! Ce moment qui paraît interminable ne durera pourtant que cinq minutes, après quoi, tout reprend son cours normal. Julien veut prendre l'air. Pas de chance, juste devant la porte: - Alors là... - Le jeune voleur qu'il avait vu l'après-midi s'apprêtait à sonner. 


\begin{abstract}
"Je suppose que vous êtes un des amis d'Alain?".
"Oui, c'est cà".

- A quoi bon dire quelque chose, ce n'est pas mon jour. -

- "Vous ne sauriez pas ouvrir une voiture sans clefs par hasard?".

- "Non, mais Alain doit sûrement savoir lui!...".

- "J'ai laissé mes clefs à l'intérieur".

- Décidément, il faut que je me repose. Pour une fois que je vois quelque chose qui sort de l'ordinaire, il faut que je me trompe. C'est vrai qu'il n'a pas une tête de voleur, j'aurai dû m'en douter... - (Ne parait-il pas moins noir, lavé de tous soupçons?). Perdu dans le western de ses rêves, le "caïd endormi" continue son séjour; à l'affût du moindre faux pas. Combien de fois a-t-il été agressé (dans ses rêves)? Justicier de bandes dessinées, il attaque de son fauteuil la mouche qui rode autour de lui... Un jour flottera-t-il, le drapeau blanc de ses nuits?
\end{abstract}

(A.E. $3^{\text {eme }} 2$ )

\title{
LE JEU DES DISTANCES CULTURELLES.
}

Si comme nous le pensons, "le problème de la lecture" réside essentiellement dans l'incapacité du système scolaire à "inscrire l'acculturation qu'il propose dans des pratiques culturelles propres aux milieux sur lesquels il travaille "(31) il va de soi que la relation de notre expérience pédagogique n'a pas qu'un intérêt local(isé) et anecdotique. Ce qui est mis en jeu dans un collège peut l'être au collège, en général. A vrai dire, les pratiques réelles des sujets sociaux réels sont rarement prises en compte par l'équipe éducative. Nous nous proposons maintenant d'examiner quelques concepts clés qui permettent de penser cette problématique socio-culturelle et de donner les moyens théoriques d'une autre pédagogie de la lecture, étant entendu que le travail d'une équipe sur une année scolaire (ce dont nous venons de rendre compte) n'avait pas l'ambition de soulever et d'affronter systématiquement et simultanement tous les problèmes liés à ce type de démarche (lectures écritures de textes de types très différents, par exemple). On lira dans l'article de $Y$. Reuter un programme de travail qui vise à faciliter l'intégration des lecteurs dans l'univers du livre et à reconnaître l'existence de livres dans l'univers du lecteur.

\section{1. - Prendre de la distance.}

Dans les faits, entre les quatre murs de la salle de cours tout se passe comme si l'enseignant prenait fort peu de distance par rapport aux représentations dominantes en matière de communication, de culture et de lecture.

\section{1. - La communication.}

Porté à croire ses propres modèles nécessaires à l'éducation (jadis à l'édification) de son public, le maître tend à postuler qu'avec plus ou moins de résistance, de soumission oú de complicité le lecteur est modelé par le texte lu, qu'il devient semblable à ce qu'il reçoit, " qu'il est imprimé par et comme le texte" qui lui est imposé (32). Cette idéologie de la "consommation-réceptacle" liée à une pédagogie de l'autorité et des "autoritas" se manifeste scolairement par l'existence des lectures dirigées, des morceaux choisis, des livres "classiques", des livres du maître, des questionnements et des questionnaires à sens unique... Ce type de pratique suppose qu" "assimiler" signifie nécessairement "devenir semblable à " ce qu'on absorbe et non le "rendre semblable" à ce qu'on est, le faire

(31) J. Hebrard, "Ecole et Alphabétisatior au Xixème siecle", Note critique in Anna/es E.S.C., Janvier-Fevrier 1980, p. 76.

(32) M. de Certeau, "Arts de falre", in Linvention du quotidien, tome I, chap. XII. 
sien, se l'approprier ou réapproprier" (33). C'est pourquoi le même professeur qui expose doctement le schéma de la communication, dès les premiers cours de grammaire modernisée, en expliquant l'efficace spécifique du destinataire dans la compréhension du message, dénie le plus souvent toute productivité réelle aux lectures de ses élèves. Les tests (et retests) de lecture les plus communs et les modes improductifs de lecture qu'ils induisent en amont et en aval reposent exemplairément sur cette conception mécaniste et instrumentale qui oblitère l'activité dans le pluriel du texte (34).

C'est oublier que lire c'est "pérégriner" dans le système du texte, "réserve de formes qui attendent du lecteur leur sens" (35) que comme dit Voltaire, "les livres les plus utiles sont ceux dont les lecteurs font eux-mêmes la moitié "(36) que "plus le texte est pluriel et moins il est écrit avant que je le lise" (37) en somme qu'il y a toujours possibilité d'interaction signifiante entre le texte et son lecteur.

Or, si les "dispositifs socio-politiques de l'école (...) isolent de ses lecteurs le texte tenu par le maître", derrière cette mise en sens socialement autorisée et légitimisée se cache "l'activité silencieuse, transgressive, ironique ou poétique de lecteurs qui conservent leur quant-à-soi dans le privé et à l'insu des "maîtres" (38).

Lire "est un braconnage "(39) mais Azouz, le gône du Chaâba, le gosse des anciens bidonvilles lyonnais qui retrouve à sa manière et avec émotion dans " $L a$ ficelle "de Maupassant l'économie de subsistance qu'il connaît de si près est vertement remis à sa place, pour cette appropriation déplacée. Comme le conclut justement le narrateur lui-même, le même mépris et "la même méprise" qui s'étaient abattus sur le pauvre vieil homme du village normand " $m$ 'avait frappé " par la main de mon professeur (40).

Autant dire que l'enseignant a intérêt à connaître les caractéristiques socioculturelles, et non simplement scolaires, qui définissent les jeunes lecteurs à acculturer et non à déculturer (41).

L'ouverture sur le quartier et la constitution d'un lectorat ont précisément pour effets et pour mérite de placer livres, lecteurs et lectures au cœur de cette problématique. Ce dispositif conduit nécessairement à (re)considérer la culture dont sont porteurs les élèves et leurs familles, et les lectures qu'éventuellement ils pratiquent.

(33) idem, ibidem

(34) II nous semble intéressant de rappeler ici la féconde conception barthésienne de la lecture.

- le lecteur : ce n'est pas "un sujet innocent, antérieur au texte et qui en userait ensuite comme d'un objet à démonter ou d'un lieu à investir. Ce "moi" qui s'approche du texte est déjà lui-même une pluralité d'autres textes, de codes infinis, ou plus exactement: perdus (dont l'origine se perd)"

- lire : c'est un travail de langage, un "acte léxéologique" voire "lexéographique" lorsque l'on écrit sa lecture ; ce n'est pas "un geste parasite le complément réactif d'une écriture que nous parons de tous les prestiges de la création et de l'antériorité".

-le texte àlire: "Quelle est la somme du texte? Des sens peuvent bien être oublies, mais seulement si l'on choisit de porter sur le texte un regard singulier". La lecture ne consiste pas à "arrêter la chaîne des systèmes, à fonder une vérité, une légalité du texte et par conséquent à provoquer les "fautes" de son lecteur : elle consiste à embrayer ces systemes (...) selon leur pluralité (...) : je passe, je traverse, jarticule, je déclanche, je ne compte pas. L'oubli des sens $n^{\prime}$ est pas matière à excuse, defaut malheureux de performance; $c^{\prime}$ est une valeur affirmative (...): c'est précisément parce que j'oublie que je lis. (Barthes, $S / Z$, Points, Seuil; 1970, pp. 16 à 18).

(35) M. de Certeau, op. cit.

(36) Voltaire, Preface au Dictionnaire philosophique.

(37) R. Barthes, op. cit.

(38) M. de Certeau, op. cit.

(39) idem, ibidem.

(40) A. Begag. La gone du Chasba, Coll. Virgule, 1986, pp. 220-221.

(41) C'est le travail décrit en II qui a amené à s'informer, dans une perspective pédagogique, sur les parametres démographiques, ecologiques, sociaux, économiques et culturels du quartier. II ne nous était pas venu à l'idée auparavant d'essayer, par exemple, de chiftrer le nombre de parents analphabetes ou francophones. Cette question pouvait avoir un intérêt humain mais de toute manière les résultats obtenus n'auraient pas tiré à d'autres consequences.. 


\section{2. - La culture.}

La théorie dominante de la culture assimile volontiers toute culture à la culture cultivée, à la culture lettrée; même si l'on retient ce modèle ethno-centrique et socio-centrique de la culture (Beaux-Arts et Belles-Lettres) on s'apercoit que le clivage n'est pas systématique, entre école et quartier, fût-il populaire. Les situations de multi-culture sont le plus souvent internes au systeme culturel (42).

On sait par exemple que "l'adolescence et la jeunesse constituent la période de la vie où l'activité de lecture est la plus grande "(43); on sait aussi que la plupart des indicateurs concernant la lecture en France sont en hausse (44), qu' en zone rurale la lecture quotidienne de la presse est plus élevée que la moyenne nationale (45) et qu'une certaine "démocratisation... par l'ignorance" de l'histoire de la littérature rassemblent la plupart des français (46).

Le rappel de ces faits n'est pas destiné à minimiser la gravité et la difficulté des problèmes mais à permettre au moins de les situer dans des perspectives plus contrastées. Il s'agit aussi d'éviter que des positions nourries de visions catastrophiques se radicalisent et d'alimenter des fantasmes de lettrès sur l'obscurantismes des campagnes ou autres.

Une approche un peu fine des phénomènes de domination culturelle montre d'autre part que les pratiques culturelles des dominés (comme celles des dominants d'ailleurs) ne sont pas uniformes et stabilisées une fois pour toutes mais parcourues de fractures multiples; en effet "I'appartenance à une communauté de vie et de travail, que ce soit le village ou l'usine, ne commande pas forcément une unité dans les conduites culturelles" (47).

Dans sa remarquable enquête sur Les jeunes travailleurs et la lecture, $\mathrm{N}$. Robine nous rappelle brutalement que " $80 \%$ des ouvrages produits en France sont lus par $10 \%$ de la population" (48) mais elle montre aussi combien, dans une population (les jeunes travailleurs) "en apparence homogène et choisie en fonction de critères de regroupements culturels" il existe de types opposes. "Du lecteur de livres, qui n'appartient pas obligatoirement au secteur tertiaire, au nonlecteur militant s'échelonne toute une gamme d'attitudes et d'habitudes culturelles" dont N. Robine propose une typologie en cinq groupes (initiés, nouveaux lecteurs, modérés, récalcitrants, accaparés) (49). C'est en jouant sur ce feuilleté de la structure culturelle que l'on peut "accrocher" des lectures au quartier; il existe toujours ainsi une marge de manœuvre où sont possibles des effets de transformation, aussi limités apparaissent-ils, surtout quand le collège est inséré dans la ville moderne composée "ni d'une, ni de deux, ni de trois cultures; encore et toujours Babylone, elle est creuset de cultures parce qu'elle est contact de micro-cultures qui s'interpénètrent et s'influencent réciproquement" (50).

(42) P. Longchamp. op. cit.

(43) Les pratiques culturelles des jeunes, in Développement culturel, Bulletin du Service des Etudes et Recherches, La Documentation Française, no 62 , avril 1985

(44) Pratiques culturelles des Français, description socio-démographique, Evolution 1973-1981, Dalloz, 1982, pp. 65 a 81.

(45) Les pratiques culturel/es des ruraux, in Développement culturel, Bulletin du Service des Etudes et Recherches. La Documentation Française. no 61, fevrier 1985

(46) Selon un sondage de la S.O.F.R.E.S. sur les connaissances litteraires des Français publié in Le Monde du 31 janvier 1986.

(47) R. Chartier, "La culture en question", in Les intermédiaires cu/ture/s, Champion, 1981, p. 673

(48) N. Robine, op. cit., p. 20.

(49) idem, ibidem, pp. 56 à 67.

(50) J. Molino, "Combien de cultures?". in Les intermediaires cu/ture/s, p. 635 
La coupure est loin d'être absolue encore entre les lectures célébrées par I'instruction scolaire et certaines lectures adolescentes et/ou populaires. II y a rencontre, rencontre souvent inapeçue, sinon circulation de traits culturels, entre la lecture d'un brave et honnête roman "qui marche bien en $3^{\text {eme " }}$ "et la lecture de tels romans sentimentaux à succès. Si les jeunes filles lisent plus et réussissent mieux que les garçons c'est peut-être... qu'Harlequin est déjà dans la classe. L'enseignement traditionnel de la lecture $n^{\prime}$ amène-t-il pas les élèves les plus scolaires à rechercher des fictions qui relèvent d'une esthétique réaliste, d'une thématique conformiste (famille, morale, paysage vs sexe, mort, classes), d'une psycho-logique de la narration, d'une stylistique du cliché et d'une idéologie du sens commun ? Combien de fois n'a-t-on pas "expliqué " la passion de Tristan et Yseult ou celle de Rodrigue et de Chimène comme une idylle perturbée, combien de fois n'a-t-on pas donné à lire tel "grand" roman comme une romance... ? Attend-on autre chose d'une bonne rédaction de $3^{\text {ème }}$ qu'elle soit "lisible", bien écrite et réhaussée, finalement, des meilleurs sentiments. Bref les paralittératures (voir Pratiques $n^{\circ} 50$ ) ne seraient pas refoulées si vivement si les dissensus patents ne renvoyaient pas d'évidence à un consensus latent. D'un cerrtain point de vue enfin, enseignants et enseignés des quartiers populaires se ressemblent ou se complètent plus qu'ils ne s'opposent. Par fonction, les professeurs de ces collèges sont dans cet entre-deux qui sépare la culture de l'élite de celle des classes populaires. Placés au carrefour de deux massifs culturels, ils naviguent volens nolens entre deux mondes. Cette situation particulière et ambiguë est aussi dynamique et privilégiée car si l'échange est inégal, il peut demeurer bilatéral. En effet les élèves occupent, par position, un rôle symétrique bien que décalé et beaucoup plus dépendant, un peu comme ces bons domestiques d'autrefois dont les manières de dire et de faire singeaient puis mimaient peu à peu celles de leurs maîtres tout en restant en contact permanent avec des bribes de culture populaire. Mais à la différence de ces serviteurs nos élèves sont à la croisée de processus d" "enculturation" (participation à la subculture du groupe socio-familial) et d" "acculturation" (intégration à la culture hégémonique socio-scolaire) (51).

A condition de proposer les médiations pédagogiques nécessaires, ces jeunes apprenants peuvent s'approprier des modalités de lectures diverses. Or l'imposition d'une définition restrictive des lectures nécessaires (conservatisme du corpus officiel) et la dévalorisation des pratiques lecturales extra-scolaires (archaïsme de l'actuel BEPC) ne permettent pas à d'éventuelles interactions culturelles de se développer. Ainsi la lecture scolaire, plus orientée vers la reconnaissance de quelques classiques, l'introspection psychologisante et la maîtrise d'une expression écrite, "lecture captive" prescrite par des obligations arbitraires (52) ne saurait viser la mise en place d'un habitus lectural authentique.

(51) A.-M. Cirese, "Altérité et dénivellement culturels dans les sociétés dites superieures", in Ethnologia Europaea, Volume I, no 1, 1967. pp. 12 à 69. Pour éviter de confondre les élèves "intégrés à la culture vernaculaire (...). solidement enracinés dans la culture des rues" et ceux qui la rejettent ou en sont rejetés, hic et nunc, il serait sans doute intéressant d'introduire dans l'établissement sinon dans la classe un métis culturel, jeune homme socialement et culturellement proche des élèves mais plus âgé et plus diplômé qu'eux; son rôle consisterait à faire connaître aux enseignants "les intérêts particuliers des élèves" et maintiendrait le contact avec ces mêmes éleves. sur le quartier, comme on dit.

Le profil et le travail de l'animateur dant nous avons parlé correspond en partie à ce type d'intermédiaire que Labov réclame pour les écoles des ghettos noirs américains. (W. Labov. "Echec de l'apprentissage de la lecture et position par rapport au groupe de pairs", in Le Parler ordinaire, Ed. de Minuit, 1978, pp. 174-175).

(52) Le rapport sur Les bibliothèques en France, Ministère de la Culture. Dalloz, exprime les mêmes réserves. 
Au total, en perpétuelle situation de compromis forcé et réciproque, ces intermédiaires culturels ont, nous semble-t-il, un intérêt partagé à rechercher leurs points de rencontre, à opérer un ajustement, une véritable " transaction symbolique", rendue possible parce qu'il n'est pas "de discours qui soit propre à une classe donnée, ni de relations univoques dans le jeu des emprunts" culturels (53).

\section{3. - La lecture.}

La reconmaissance des pluralités et des communautés culturelles ne suffit pas. II s'agit de souligner aussi "la pluralité des usages d'un même objet culturel", c'est-à-dire admettre "qu'un bien culture/ n'a de signification qu'à travers les différentes stratégies d'interprétation qui s'emparent de lui" $(54)$ et complémentairement se demander, le cas échéant, ce que c'est que "traiter de façon savante un produit non savant" (55). Un double obstacle se présente. Par leur formation universitaire surtout mais aussi par leur origine sociale, les enseignants sont souvent mal préparés à connaître et à reconnaître, dans leur existence même et a fortiori leur logique spécifique, les pratiques et les valeurs culturelles des classes populaires.

Annie Ernaux dont le père fut garçon de ferme, puis ouvrier d'usine, petit commerçant enfin, s'attache à décrire avec minutie l'héritage culturel des dominés qu'elle a dû oublier, non sans déchirure, pour devenir professeur de lettres, et se marier bourgeoisement. Elle rapporte par exemple que ce qui rendait "violent" son grand-père c'était surtout "de voir chez lui quelqu'un de la famille plongé dans un livre ou un journal " (56) et que ce qui énervait son père c'était de la voir "s'user la santé " à rester plongée dans les livres "mettant sur leur compte (son) visage fermé et (sa) mauvaise humeur" (57). Elle écrit, lucide:

"Le déchiffrement de ces détails s'impose à moi maintenant avec d'autant plus de nécessité que je les ai refoulés, sûre de leur insignifiance. Seule une mémoire humiliée avait pu me les faire conserver. Je me suis pliée au désir du monde où je vis (désormais), qui s'efforce de vous faire oublier les souvenirs du monde d'en bas comme si c'était quelque chose de mauvais goût" (58).

La conclusion de ce récit d'une acculturation est dépourvue d'ambiguïté : "j'ai fini de mettre au jour l'héritage que j'ai dû déposer au seuil du monde bourgeois et cultivé quand j'y suis entrée "(59). Ce phénomène semble lié à la production des intellectuels traditionnels voués à la reproduction des sociétés culturellement hiérarchisées. G. Duby montre par exemple que si les clercs du Moyen-Age pouvaient etre de "povre estrace "ils ne devenaient clercs et ne suivaient une trajectoire culturellement ascendante qu'à condition d'oublier, sinon de renier, le monde des "illetterati" où ils étaient nés. Plus près de nous, F. Muel a analysé comment l'origine sociale des instituteurs de la Belle Epoque et leurs études à l'Ecole Normale les amenaient à reconstruire des rapports esthétiques et folkloriques à la paysannerie dans laquelle ils travaillaient et comment leur rapport au monde ouvrier était marqué par la "négation de l'usine et des rapports de production moderne" (60).

\footnotetext{
(53) R. Chartier, op. cit., p. 674

(54) idem, ibidem, p. 675.

(55) P. Bourdieu, La sociologie de la culture populaire, in Le handicap socio-culturel, en question, in C.R.E.S.A.S., 1981, p. 119.

(56) A. Ernaux, op. cit., p. 25

(57) idem, ibidem, p. 80.

(58) idem, ibidem, pp. $72-73$

(59) idem, ibidem, p. 111.

(60) F. Muel, "Les instituteurs, les paysans et l'ordre républicain", Actes de la recherche en sciences sociales, no 17. 18. novembre $1977 \cdot$ p. 39
} 
Dans la mesure où les représentations culturelles entrent dans la définition même des valeurs culturelles, attirer l'attention sur ces phénomènes de méconnaissance semble nécessaire. De plus comme l'écrivait $H$. Dudebout dans son rapport officiel - "Ensemble, refaire la ville "- le refus de tenir compte et d'assumer par exemple la réalité populaire de ces quartiers où dominent les ouvriers est "stérile voire dangereux" (61). Toutefois, s'il est vrai que "les spécificités de la population de ces quartiers ne sont pas toujours celles dont on parle et qui déterminent les positions et parfois les procès d'intention des divers partenaires " (62), il n'est pas aisé, actuellement, de se doter des moyens théoriquement nécessaires pour saisir cette réalité notamment dans ses dimensions culturelles.

En effet si dans la société française le groupe social que constituent les ouvriers est le plus nombreux et peut-être le plus divers (des prolétariats les plus déracinés aux ouvriers les plus localistes), il est aussi un de ceux dont on parle le moins "parce qu'il prend rarement la parole sur lui-même, mais aussi parce que littérature, cinéma, journalisme ne mettent presque jamais en scène des ouvriers" (63). On remarque ainsi que les ouvriers sont peu présents dans l'univers des représentations, que très rares sont les romans ou les œuvres de fiction dans lesquelles des ouvriers contemporains apparaissent comme personnages principaux (l'ouvrier n'est ni héros de roman ni support aux images publicitaires). Dans le même ordre d'idées on note que si les membres des classes supérieures diffusent sur eux-mêmes de nombreuses représentations littéraires, journalistiques et cinématographiques et si la nouvelie classe moyenne est une classe dont on parle et qui se parle, le nombre d'études portant sur les productions symboliques ouvrières est très faible: "une classe toute entière se trouve ainsi définie culturellement improductive" et son rapport à la culture légitime (école et institutions) est logiquement considéré comme "malheureux" (64). De son côté N. Robine indique, pour situer l'originalité de sa recherche, qu'aucune publication importante et récente n'a eu lieu sur son sujet qui associe "les milieux du travail et la lecture " (65) ; elle rapporte aussi que l'obstacle institutionnel majeur rencontré pour réaliser une enquête commandée pourtant par le Service des Etudes et Recherches du Ministère de la Culture fut l'Education Nationale qui "interdit par circulaire aux directeurs des L.E.P. de fournir les noms et adresses "des jeunes gens indispensables à son travail parce que, estime-t-elle, "une enquête sur la lecture dans les milieux défavorisés dérange l'image que l'Education Nationale souhaite donner d'elle-même" (66).

Il est tout aussi difficile de se repérer dans la "nébuleuse mouvante et diverse des cultures des jeunes "dont la cohérence interne institue et maintient sa distance avec la culture des autres ; la saisie des connivences culturelles est d'autant plus délicate que nos jeunes élèves sont "en cours de transformation sociale et culturelle, donc susceptibles de jouer plusieurs rôles, d'en quitter un pour un autre, puis de revenir au premier ou de tenter des combinaisons "dans un double

\footnotetext{
(61) H. Dudebout, op. cit., p. 57

(62) idem, ibidem.

(63) M. Buzun, "Les recherches récentes sur la culture ouvrière : une bibliographie" in Terrain no 5 , octobre 1985, pp. 46 à 56

(64) idem, ibidem, p. 47

(65) N. Robine, op. cit., p. 23

(66) idem, ibidem, p. 34. L'indigence des enquêtes officielles sur les lectures des jeunes est, elle aussi, remarquable (voir l'article de P. Lepape: "Que lisent les jeunes?". in Le Monde du 4 octobre 1985).
} 
mouvement de "rejets et de demandes simultanés" (67) par rapport aux lectures scolairement légitimées. Cette ambivalence est d'ailleurs de règle dans les changements culturels dont le rythme et secondairement l'étendue déterminent une acculturation "réussie" ou bien une véritable déculturation : il faut que puissent jouer "les actions régulatrices et les réactions adaptatives, emprunts, rejets sélectifs et/ou réinterprétation assimilatrice" $(68)$ sous peine de produire, comme on voit, des sabirs lecturaux ou si l'on veut des lectures bidonvilliseees.

Méconnaissance malheureuse, méconnaissance historique ou méconnaissance programmée, les diverses modalités de cette distance culturelle sont redoublées bien souvent par l'aveuglement des enseignants sur leur propre culture, l'arbitraire et la prégnance de leurs rapports à la lecture et de leurs usages des lectures.

Dans son étude déjà citée sur les instituteurs de la République, au début du siècle, F. Muel montre très bien les mécanismes socio-culturels qui les ont conduits au moins dans leurs témoignages à valoriser la lecture et à survaloriser la littérature bourgeoise:

"dans cet univers professionnel marqué par la restriction - rappel de la double distance sociale et imposition du respect culturel - la lecture (...) permet de substituer à l'isolement social (souligné par les instituteurs lorsqu'ils se disent méprisés par la bourgeoisie et jalousés par le peuple, ou lorsqu'ils précisent l'absence de relations sociales en dehors du cercle professionnel) le monde imaginaire de la "complicité" culturelle, "la société des livres" (69).

Les spécialistes eux-mêmes se laissent abuser. Certains en prennent conscience in extremis, comme ces sociologues suisses, spécialistes des loisirs populaires, qui reconnaissent, "au terme d'une recherche", que les définitions qu'ils proposent souffrent de "socio-centrisme" et que la variété même de leur objet d'étude (dont la lecture fait partie) y est "mal reconnue"! (70).

D'autres fois l'enfermement culturel est plus étonnant encore. Ph. Meirieu par exemple signale avec beaucoup de clairvoyance le risque de folklorisation et de marginalisation festives des motifs culturels exotiques les plus voyants et regrette que l'on passe sous silence d'autres formes culturelles, "plus proches et pourtant moins visibles, comme la culture rurale, ouvrière, ou encore ces ébauches culturelles qui se créent à la périphérie de nos cités" (71). Cette position, affichée, ne l'empêche pas de multiplier des propositions culturelles strictement classiques: "un poème de Villon, une symphonie de Beethoven, un tableau de Picasso, nous imposent, un temps, le silence (...). Pouvons-nous nous passer de Goya (...), de Racine (...), de Mozart (...), d'Eluard (...) ?" (72).

(67) $\mathrm{Ph}$. Longchamp, op. cit.; sur les formes spécifiques de la culture juvénile voir L. Chambard, "Culture des parents, culture des enfants" in Le Français Aujourd'hui, no 70, pp. 19 a 22: et Ch. Epinat, "Changer de connivences.., Supplement au Français Aujourd'hui, no 60, déc. 82. On trouvera dans Ethnologie française, janvier-mars 1986. pp. 93 à 105 le compte rendu d'un récent colloque consacré aux "Classes d'áge et Sociétés de Jeunesse "et dans Education Formation Societé : Recherche pour demain, INRP 1986, le compte rendu des travaux de la commission no 5, "Que savons-nous des jeunes dans leur mode de vie, leurs rapports à l'education, à la culture. à l'emploi ?". pp. $151-154$

(68) P. Bourdieu et A. Sayad, Le déracinement, Ed. Minuit, 1964, pp. 29-35.

(69) F. Muel, op. cit.. p. 54.

(70) Ch. Lalive et alii, Temps libre, culture de masse et cultures de classes aujourd'hui. Coll. Regards sociologiques, Ed. Favre, 1982, pp. 171-172, nute 1.

(71) Ph. Meirieu, L'école mode d'emploi, ESF, 1985, p. 104.

(72) idem, ibidem, p. 91. Dans ses "Quelques mots sur l'instruction publique en France" (1872) dont l'interêt historique reste considérable, $\mathrm{M}$. Bréal dénonçait le décalage entre le nouveau et nombreux public à instruire et l'aristocratisme de la culture à acquérir : "Les livres que Bossuet a composés pour le Dauphin servent aujourd' hui àl'ins. truction des enfants de notre bourgeoisie". 
Ce "nous" vit rarement à la périphérie de nos cités... C'est ainsi que l'on produit peut-être des livres sans lecteurs et des lecteurs sans livres.

Prendre de la distance permet ainsi, sans aucun doute, de mieux situer les noyaux durs ou s'enkystent la violence symbolique et de mieux maîtriser les effets de domination symbolique. Mais ce discours risque à son tour de paraître à la fois vulgaire et terroriste; vulgaire parce qu'il transgresse la limite sacrée qui distingue le règne pur de la lecture du domaine brut et brutal de la sociologie de la lecture, terroriste parce qu'il prétend enfermer l'expérience intime et ineffable de la lecture dans les filets ordinaires d'un savoir positif.

Ce risque vaut la peine d'être couru tant il nous semble que si vulgarité intellectuelle et terrorisme culturel il y $a$, c'est bien "dans les verdicts péremptoires qui, au nom du goût, renvoient au ridicule, à l'indignité, à la honte, au silence", dans ces coups de force "symboliques" par lesquels les dominants essaient d'imposer leurs propres lectures (73).

\section{2. - Eloignement.}

Nous venons de baliser quelques-uns des domaines à travailler soit parce que leur méconnaissance perturbe ou pervertit les initiatives pédagogiques et leurs effets escomptés soit au contraire parce qu'ils constituent des points de contact culturel privilégiés. Faire apparaître ainsi des blocages à dépasser ou des espaces à (ré)investir, c'est dessiner des programmes de travail (sur soi, sur les autres et avec les autres), c'est essayer de dire que malgré la complexité des difficultés une autre pédagogie de la lecture est possible.

II ne faudrait pas pour autant se dissimuler que les pratiques de lecture s'ordonnent selon les catégories socio-culturelles de domination et de dépendance. En effet, s'il est difficile de conclure à une baisse du volume global des lectures (de 1973 à 1981 il y a extension de l'audience du livre et accroissement du nombre des petits lecteurs), il faut néanmoins préciser "qui lit".

Les écarts les plus importants sont liés à l'âge comme on l'a vu (maximum de 15 à 24 ans, minimum de 40 à 60 ans), à l'origine (les individus issus de parents cadres ou exerçant des professions libérales se distinguent nettement des autres), aux statuts socio-professionnels (même type de rupture que précédemment), à la taille de l'agglomération (on lit plus à Paris qu'en province et davantage dans les villes de plus de 100000 habitants que dans les autres), aux diplômes (les titulaires du bac ou plus différent très sensiblement des autres), au sexe (il y a plus de lectrices que de lecteurs) et à la situation de famille (les célibataires fréquentent plus les livres que les personnes mariées).

Ainsi, près de $3 / 4$ des Français âgés de 15 ans et plus lisent au moins un livre par an mais une fréquence plus représentative d'un certain habitus lectural (à partir de 25 livres par an) ramène le chiffre à seulement 18,6\% Ces grands lecteurs sont les personnes appartenant aux milieux de cadres supérieurs et professions libérales, les élèves et étudiants, les bacheliers et diplômés de l'enseignement supérieur, les parisiens enfin (74).

II y a donc lecteurs et lecteurs; mais il y a aussi lectures et lectures. Les préférences vont en effet vers des livres différents ce qui suppose du point de vue des propositions d'action des modalités différentes selon les publics considérés.

(73) P. Bourdieu, La Distinction, critique sociale du jugement, 1979, p. 597

(74) Pratiques culturelles des Français, ibidem. 
Etant entendu que les romans (75) arrivent largement en tête des livres les plus lus dans toutes les catégories socio-démographiques sauf une (les gros commerçants et industriels) ceux qui lisent le plus (et possèdent le plus de livres) sont aussi ceux qui lisent le plus, tendanciellement, les genres légitimés (littératures classiques et essais). Inversement les ouvrages non légitimés (ouvrages pratiques et dictionnaires par exemple) sont des lectures populaires (76). Si l'on ordonne ces constats selon l'axe classes populaires (considérées dans leur ensemble) et classes moyennes (considérees dans leur sous-groupe " professeur producteur artistique") (77), on observe une disposition croisée des pratiques. Les professeurs lisent aussi peu d'histoires sentimentales que les employés lisent d'essais philosophiques et en gros alors que les lecteurs populaires se portent avec une prédilection croissante vers les récits de voyage, les aventures policières et les récits historiques, les agents culturels préfèrent les ouvrages modernes ou classiques voire la poésie. Au croisement de ces goûts, par contre, l'écart qui concerne la lecture quotidienne de la presse reste faible.

Les propensions à lire, et à lire tel livre plutôt que tel autre sont donc liées de manière transversale et surdéterminante à l'appartenance socio-culturelle, même si aucune lecture n'est le monopole d'un groupe social et si aucun groupe social ne pratique unanimement un même type de livres.

On peut cependant ajouter que les pratiques de lecture ne sont pas indépendantes des pratiques culturelles en général lesquelles s'organisent ainsi en subcultures, systèmes structurés de valeurs, de normes et en définitive de choix. Ce sont les mêmes personnes qui à la fois lisent le plus, vont le plus au cinéma, au concert, à l'opéra, au théâtre, fréquentent le plus les musées, participent le plus à des associations culturelles ou artistiques etc... (78).

Les formes populaires de la culture ont aussi leur logique, systématique et spécifique; c'est dire que les inégalités culturelles sont aussi des différences voire des oppositions distinctives. Le choix n'est donc pas à faire entre l'étude des inégalités culturelles et celle des différences: il faut approcher les inégalités et les différences, les différences dans l'inégalité. Rien ne peut dénier aux individus comme aux groupes "l'invention du quotidien", la négociation de ce qu'ils ont pour en faire ce qu'ils sont, le marquage distinctif sinon distingué de leur appartenance culturelle.

Ainsi, de son père qui lui déclare un jour derrière le comptoir de son petit bar-épicerie de province: "Les livres, la musique, c'est bon pour toi. Moi, je n'en ai pas besoin pour vivre" (79), Annie Ernaux dit:

"Il était gai. /l blaguait avec les clientes qui aimaient rire. Grivoiseries à mots couverts. Scatologie. Ironie, inconnue. Au poste il prenait les émissions de chansonniers, les jeux. Toujours prêt à m'amener au cirque, aux films bêtes, au feu d'artifice. A la foire, on montait dans le train fantóme. l'Hymalaya, on entrait voir la femme la plus grosse du monde et le Lilliputien. "I n'a jamais mis les pieds dans un musee. "I

\footnotetext{
(75) idem, ibidem

(76) idem, ibidem. La pratique du livre technique et documentaire jointe a l'utilisation des outils didactiques qui peu vent permettre d'élargir le champ des curiosités et des connaissances s'impose au college.

(77) P. Bourdieu, op. cit., p. 619

(18) Les actıvités socio-cuiturelles ou socio-éducatives légitimes mais extra-scolaires dont les familles seules ont l'initiative et qui ont " une très forte incidence sur le développement intellectuel des enfants" en ce qu' elles confortent un certain habitus culturel, sont liées presque entièrement à la "différenciation sociale". (d'après A. Mingat et J. Pierrot, "Les depenses des familles pour l'éducation des enfants" in L'enfant, la famil/e et /'école, E.S.F., 1981 , pp. 14 à 37

(79) A. Ernaux, op. cit., p. 83
} 
s'arrêtait devant un beau jardin, des arbres en fleur, une ruche, regardait les filles bien en chair. II admirait les constructions immenses, les grands travaux modernes (le pont de Tancarvillel. Il aimait la musique de cirque, les promenades en voiture dans la campagne, c'est-à-dire qu'en parcourant des yeux les champs, les hêtrées, en écoutant l'orchestre de Bouglione, il paraissait heureux. L'émotion qu'on éprouve en entendant un air, devant des paysages, n'était pas un sujet de conversation. Quand j'ai commencé à fréquenter la petite-bourgeoisie d'Y..., on me demandait d'abord mes goûts, le jazz ou la musique classique, Tati ou René Clair; cela suffisait à me faire comprendre que j'étais passée dans un autre monde" (80).

\section{3. - Tenir à distance.}

II n'est pas étonnant que dans ces conditions des pratiques affrontées se traduisent par des affrontements, et parfois des affronts, dans la pratique. Pour ceux qui jouissent d'un solide capital culturel, hérité de la famille et/ou certifié par l'institution, pour ceux qui profitent par habitus primaire (lié à la prime éducation) et/ou par habitus secondaire (lié à l'école, à la trajectoire sociale) d'un véritable habitus lectural (81), bref pour ceux qui pratiquent le Littré, il est deux types de lecteurs : les littrés... et les illittrés, alphabètes ou analphabètes confondus. De ce point de vue, l'accent peut être mis au nom du relativisme culturel soit sur l'autonomie et la cohérence symbolique des pratiques culturelles illittrées (et c'est le côté populiste des littrés: "Pourquoi après tout, si çà leur plait, c'est leur droit ") soit au nom du légitimisme culturel sur les inter-relations systématiques et l'excellence hiérarchique ( $c$ 'est le côté misérabiliste des littrés: "Moi, jamais on me fera lire çà, c'est débile ") (82).

Mais de leur côté, les dits illittrés peuvent faire front et distance tenir soit en reconnaissant la liberté souveraine aux littrés d'accomplir leur intellectualité (c'est l'élitisme des illittrés: "c'est une tête. II lit sans arrêt et même écrit des livres. Il en faut"), soit en méprisant la singularité distinctive de leurs travaux et en disqualifiant leur nature (c'est le poujadisme des illittrés: "Les intellectuels, c'est comme les poissons, ça pourrit d'abord par la tête").

Ces luttes symboliques agitent parfois, hantent souvent la classe; et si les niveaux de langue sont éventuellement considérés d'un point de vue cognitif et illustratif (il est vrai que le Petit Robert dit du langage populaire qu'il est "courant dans les milieux populaires des villes mais réprouvé ou évité par l'ensemble de la bougeoisie cultivée ") les subcultures populaires, elles, n'ont même pas droit de cité.

(80) A. Ernaux, op. cit., p. 65. Cette citation illustre parfaitement la profonde intrication dynamique de quatre niveaux de la realité sociétale dans la production des phénomènes culturels (appareils de production, rapports sociaux. systeme symbolique et organisation de l'espace) qu'analysent certains sociologues de la culture (Ch. Lalive et alii, op. cit.. p. 51).

On lira sur les"styles de vie". P. Bourdieu, La Distinction, et une critique du légitisme latent de cet ouvrage par C. Grignon et J.-C. Passeron, in Sociologie de la cuiture et sociologie des cultures populaires, document du G.I.D.E.S. : sur les "différenciations culturelles" voir notamment Les cultures populaires (sous la direction de G. Poujol et R. Labourie) I.N.E.P., Privat, 1979, pp. 79 à 200. Sur les principes esthétiques des cultures ouvrières lire l'analyse suggestive de $M$. Verret, op. cit.. "Les fêtes de l'instant et du nombre", pp. 153-154, "Le concert nature/" pp. 154-155 et "Plaisirs de masse, plaisirs de classe". pp. 155-156. Cet ouvrage remarquable à tout égard est le premier d'une trilogie consacrée à la condition ouvrière en Fance dans les années 80 ; le deuxième volume porte sur le travail ouvrier. Le troisième, non encore paru, analysera "La culture ouvrière".

(81) Les positions extrêmes seraient illustrées respectivement par Rousseau ("Je ne sais pas comment j'appris à lire il me semble de l'avoir toujours su "), ou par Sartre ("Je ne savais pas encore lire mais j'étais assez snob pour exiger d'avoir mes livres") et par Valentin Jameray-Duval, autodidacte exemplaire de la lecture ou par P. Rivière. jeune paysan fou de lectures secrètes dont il attend la gloire ("Je n'aurais trouvé qu' un fragment de journal qui eût servi à torcher le derriere, je le lisais...").

(82) Voir C. Grignon et J.-C. Passeron, op. cit., et Y. Reuter in Pratiques no 50. 
II n'est pas rare que ces représentations trouvent une certaine assise réaliste dans le paysage culturel parcouru ou vécu. Les groupes sociaux sont en effet très inégalement tenus à distance des équipements culturels (bibliothèques, librairies, etc) selon qu'ils habitent Paris ou la province, le centre des cités ou la banlieue, la ville ou la campagne etc... R. Escarpit et $\mathrm{N}$. Robine qui ont étudié la "répartition sociale et territoriale du réseau de production et de diffusion" ont montré que ce réseau reproduisait "une structure de classe "et que certains groupes sociaux ne rencontraient de points "culture/s " ni sur leurs lieux d' habitat, ni sur leur lieu de travail, ni sur leurs trajets (83).

De plus la distance spatiale se double bien souvent, sauf peut-être pour les couches moyennes dotées d'une certaine bonne volonté culturelle, d'une distance culturelle à ces mêmes offres. C'est dire qu'on ne saurait confondre les conditions des pratiques et les pratiques effectives. La cécité culturelle en effet, plus que le temps, l'argent ou l'éloignement, est un facteur décisif parce qu'elle traduit les investissements réels et profonds des personnes. Telle coiffeuse qui habite audessus d'une librairie classique ignore ce que la vitrine propose, d'autres passent tous les jours devant une bibliothèque municipale sans la voir, beaucoup avouent n'avoir jamais eu envie de pousser la porte de tel équipement institutionnel de lecture (84). On comprend pourquoi la mise sur le marché des livres de poche et la multiplicité de leurs points de vente n'ont pas étendu sensiblement le champ.des lecteurs mais permis par contre à ceux qui en achetaient déjà d'en acheter davantage. La sélectivité culturelle vis à vis des supports de lecture se traduit par des phénomènes de perception exclusive bien connus. "De même que de nombreux intellectuels ne voient pas les fanzines et autres comics sur le comptoir de leur marchand de journaux, de même les jeunes travailleurs ne perçoivent pas les matériels de lecture offerts par le présentoir d'un bureau de tabac" ou par les rayonnages d'une grande surface (85). Cependant la cécité sélective aux livres n'est pas également partagée. L'éloignement physique d'une bibliothèque ne constituera pas un handicap pour un professeur car sa fréquentation est comme incorporée à son univers culturel alors que pour un ouvrier spécialisé ou son fils l'éventuel éloignement physique, redoublant la distance culturelle, rendra la visite hautement improbable (86). Dans ces conditions on n'hésitera pas à "didactiser l'offre (87) d'autant que l'agencement interne de ces institutions (bibliothèques, librairies, etc...) est conçu "par des lettrés, pour des lettrés" (88).

La distance culturelle, même si elle n'est pas multipliée par la distance spatiale, peut suffire dans certains cas et certaines conditions. Qui n'a croisé au tourniquet d'une importante bibliothèque, haut lieu de la culture lettrée, une modeste employée chargée de contrôler les serviettes? Elle tricote ou lit des magazines féminins à grand tirage, comme indifférente aux livres qui la sollicitent à portée de main, comme obstinément distante et témoignant d'autres préoccupations. Elle accepterait certainement la définition que le Dictionnaire des ldées reçues donne du livre: "Quel qu'il soit, toujours trop long".

(83) Voir R. Escarpit et M. Lebas, At/as de la lecture a Bordeaux, Talence, M.S.H.A., 1979. R. Escarpit, Sociologie de /a litterature, PUF, 1968 ; et sur le village intellocrate voir $\mathrm{H}$. Hamon et P. Rotman, Les intellocrates, Ed. Complexe. 1981, pp. 13 à 27

(84) N. Robine op. cit. p. 94.

(85) idem, ibidem.

(86) M. Pinçon - Charlot et P. Rendu. "Distance spatiale, distance sociale aux equipements collectifs en lle-deFrance: des conditions de la pratique aux pratiques" in Revue française de sociologie, octobre-decembre 1982 pp. 667-668

(87) J.-C. Passeron - (intervention), pp. 285-290, in Actes du Colloque lecture et bibliotheques publiques, novembre 1982 a Henin Beaumont - Lille : office regional de la culture... 1983. p. 361.

(88) N. Robine, op. cit., p. 124 
Par un ultime retournement, la lecture et ses rituels peuvent produire de redoutables contre-effets. II est des lectures qui, vrais stigmates sociaux, marquent et démarquent leurs lecteurs. Quelle professeur déclarera à ses collègues, sans ambage et sans crainte le délit de goût, lire Delly avec délice? Quel jeune collégien des faubourgs sera assez "bécasse" pour lire au pied de son immeuble Les Contes de la Bécasse et s'attendre à quelque œillade adolescente? L'insécurité culturelle et le désir de sociabilité sont en général assez forts pour dissuader l'un et l'autre (89).

Les valeurs mises en jeu dans l'acte de lecture sont elles aussi, on s'en doute, différentes. F. Pérec posait plaisamment le problème: "Un monsieur qui lit sur une plage est-il sur la plage pour lire, ou lit-il parce qu'il est sur la plage?".

Le lectorat populaire tend à considérer la lecture comme une distraction ; lire, pratique distraite, sans lieu, cadre ni moment spécifiques n'est ni valorisé ni valorisant. Le livre n'est pas le support d'une expérience existentielle ("c'est du roman!") et la lecture le temps d'un repli distingué, au contraire (90). Ces lectures obliques, nonchalantes (91), distantes parce qu'en miettes sont des lectures de loisir, évasions sans conséquence ou parcours informatifs. II n'est pas question que pendant ce temps de loisir arraché au travail la lecture soit un travail (92). Ainsi la "lecture extensive", telle qu'elle s'est développée en Europe depuis la fin du XVIII ème siècle parmi les gens cultivés, correspondrait à l'actuel mode pragmatique de la lecture populaire (romans, journaux, lus une seule fois, en amateur, pour le plaisir, en attendant le suivant) et la "lecture intensive "qui dominait parmi les clercs jusqu'à la Renaissance serait proche des relectures réflexives, esthétisantes, discursives et professionnelles des professeurs (93).

Les stratégies des lectures en bibliothèque sont également inversées. Les élites culturelles traditionnelles, partant d'une lecture générale, procèdent par spécialisation progressive, organisent leurs lectures selon une "structure réticulaire" ; le public non traditionnel, d'amateurs, procède par élargissement progressif, suivant une démarche qui rappelle la "technique de l'épuisette". Une bibliothèque multi-médias tenant compte de ces différents types de comportements peut devenir "le lieu de rencontre de deux cultures jusque là totalement étrangères l'une à l'autre, et permettre à une nouvelle frange de lecteur d'accéder aux livres ", à un nouveau rapport aux livres (94).

La connaissance des contraintes, contradictions et conflits culturels n'entraînent pas nécessairement la reconnaissance de leur fatalité. Au contraire, cet éclairage fait apparaître les préoccupations culturelles et lecturales, les enjeux et les conditions de fonctionnement du champ lectural, et les possibilités de tranfor-

(89) Sur les effets d'auto-exclusion, on lira avec le plus grand profit A. - M. Thiesse, "Des lecteurs illettrés" in Le roman du quotidien, lecteurs et lectures populaires a la Belle Epoque, Coll. de chemin vert, 1984. pp. 11-60.

(90) A.-M. Thiesse. op. cit.

(91) R. Hoggart, La culture du pauvre, Ed. Minuit, 1970, pp. 260 et suivantes.

(92) La dichotomie temps de travail vs temps libre est particulièrement marquée dans les couches populaires salariées (voir $\mathrm{Ch}$. Lalive, op. cit. et $\mathrm{P}$. Belleville, Attitudes culturelles actuelles des travailleurs manue/s in Les cultures populaires, op. cit., pp. 93-104)

Nombre d'élèves qui ont un rapport de "dominés" aux temps d'école tendent à reproduire cette disposition domestique. Ils confirment leur "ouvriétude" en travaillant un minimum au college et en ne fichant rien à la maison... Les garçons surtout refusent la double journée. Sur le dedoublement comme moyen d'échapper à la contradiction culturelle tout en essayant de cumuler les avantages lies aux deux situations voir $P$. Bourdieu, Le déracinement. Sur les stratégies scolaires marquées par et orientées vers la "culture d'ateliers" voir P. Willis, "i'Ecole des ouvriers". Actes de la Recherche, no 24, novembre 1978, pp. 51-61.

(93) R. Darnton, Le courrier des lecteurs de Rousseau... in Le grand massacre des chats, Coll. Pluriel, 1984. pp. 285 et suivantes.

(94) M. Gault, op. cit. 
mations qui peuvent s'y jouer. Toutefois pour développer un habitus lectural, if faut tenir la distance car "quatre heures" ne suffisent pas (95). L'état incorporé du capital lectural, forme particulière du capital culturel et marque d'un habitus, suppose en effet un travail d'inculcation et d'assimilation qui précisément, comme toute accumulation personnalisée de capital, "coûte du temps"; cet investissement personnel qui est "travail du "sujet " sur lui-même" (on devrait dire "se lecturer" comme on dit se "cultiver") sera d'autant plus long qu'il faudra ou non réorienter les effets de I'habitus primaire (96).

Bref on ne devient pas plus lecteur en travaillant la largeur de ses fixations oculaires qu'on ne devient mélomane en allant seulement se faire soigner les oreilles.

(95) Allusion polémique à la potion pédagogique magique vantée dans le dossier de rentrée du Nouvel Observateur (29 août - 4 septembre 1986) intitulé: "Pourquoi nos enfants ne savent plus lire" (pp. 52-57). La série d'articles parée des prestiges de la statistique informatique est surtout remarquable par l'aplatissement techniciste des problèmes.

Une information est pourtant intéressante à méditer. II est indiqué en effet que les meilleurs lecteurs (type IV

"lecture efficace sans être pour autant performante") serait $3 \%$ en 6 ème et encore $3 \%$ en 3 ème (16 \%et $31 \%$ respectivement pour les "bons lecteurs").

Autrement dit, compte tenu de l'élimination progressive d'une masse importante d'élèves de la 6 ème à la 3 ème I'habitus lectural tend à stagner voire à se dégrader pendant les années de collège..

(96) P. Bourdieu, "Les trois états du capital culturel", in Actes de la recherche, no 30, Novembre 1979, pp. 3 à 6. 